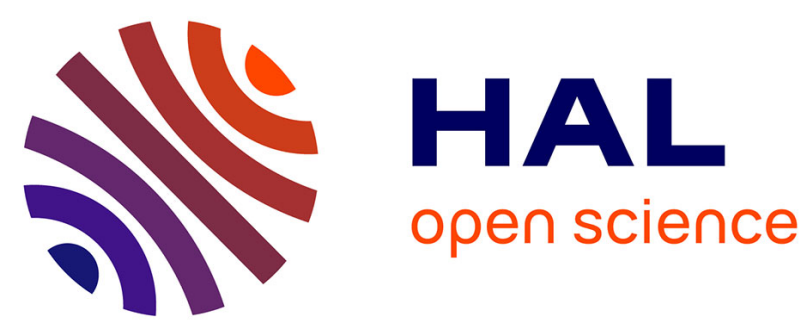

\title{
Neutron-irradiated antibody-functionalised carbon nanocapsules for targeted cancer radiotherapy
}

Julie Tzu-Wen Wang, Cinzia Spinato, Rebecca Klippstein, Pedro Miguel

Costa, Markus Martincic, Elzbieta Pach, Aritz Perez Ruiz de Garibay, Cécilia Ménard-Moyon, Robert Feldman, Yves Michel, et al.

\section{To cite this version:}

Julie Tzu-Wen Wang, Cinzia Spinato, Rebecca Klippstein, Pedro Miguel Costa, Markus Martincic, et al. Neutron-irradiated antibody-functionalised carbon nanocapsules for targeted cancer radiotherapy. Carbon, 2020, 162, pp.410-422. 10.1016/j.carbon.2020.02.060 . hal-03001282

\section{HAL Id: hal-03001282 \\ https://hal.science/hal-03001282}

Submitted on 16 Nov 2020

HAL is a multi-disciplinary open access archive for the deposit and dissemination of scientific research documents, whether they are published or not. The documents may come from teaching and research institutions in France or abroad, or from public or private research centers.
L'archive ouverte pluridisciplinaire HAL, est destinée au dépôt et à la diffusion de documents scientifiques de niveau recherche, publiés ou non, émanant des établissements d'enseignement et de recherche français ou étrangers, des laboratoires publics ou privés. 


\section{Neutron-irradiated antibody-functionalised carbon nanocapsules for targeted cancer radiotherapy}

Julie Tzu-Wen Wang a, Cinzia Spinato b, Rebecca Klippstein a , Pedro Miguel Costa a, Markus Martincic $^{\mathrm{c}}$, Elzbieta Pach ${ }^{\mathrm{d}}$, Aritz Perez Ruiz de Garibay ${ }^{\mathrm{b}}$, Cécilia Ménard-Moyon ${ }^{\mathrm{b}}$, Robert Feldman e, Yves Michel ${ }^{\mathrm{e}}$, Martin Šefl ${ }^{\mathrm{f}}$, Ioanna Kyriakou ${ }^{\mathrm{f}}$, Dimitris Emfietzoglou ${ }^{\mathrm{f}}$, Jean-Claude Saccavini ${ }^{\mathrm{e}}$, Belén Ballesteros ${ }^{\mathrm{d}}$, Gerard Tobias ${ }^{\mathrm{c}, *}$, Alberto Bianco ${ }^{\mathrm{b}, *}$ and Khuloud T. Al-Jamal ${ }^{\mathrm{a}, *}$

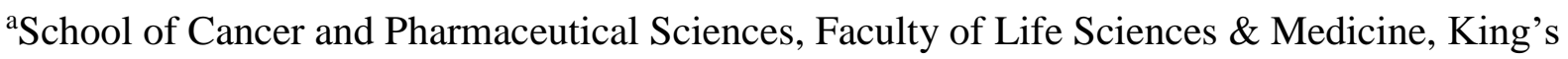
College London, London SE1 9NH, UK

${ }^{\mathrm{b}} \mathrm{CNRS}$, Immunology, Immunopathology and Therapeutic Chemistry, UPR 3572, University of Strasbourg, ISIS, 67000 Strasbourg, France

'Institut de Ciència de Materials de Barcelona (ICMAB-CSIC), Campus UAB, 08193 Bellaterra, Barcelona, Spain

${ }^{\mathrm{d} C a t a l a n}$ Institute of Nanoscience and Nanotechnology (ICN2), CSIC and the Barcelona Institute of Science and Technology, Campus UAB, 08193 Bellaterra, Barcelona, Spain

${ }^{e}$ Cis Bio International Ion Beam Applications SA, Gif sur Yvette 91192, France

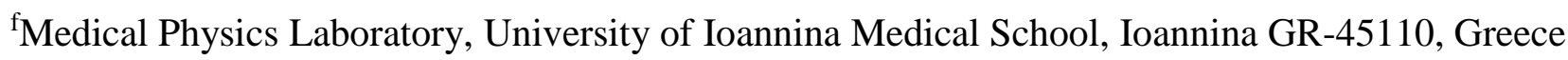

* To whom correspondence should be addressed.

E-mails: khuloud.al-jamal@kcl.ac.uk; a.bianco@ibmc-cnrs.unistra.fr; gerard.tobias@ icmab.es 


\section{Abstract}

Radiotherapy is a cancer treatment utilising high doses of ionizing radiation to destroy cancer cells. Our team has pioneered neutron activation of ${ }^{152} \mathrm{Sm}$, filled and sealed into single-walled (SWCNTs) and multi-walled carbon nanotubes (MWCNTs), to create stable and high-dose radioactive carbon nanocapsules for cancer radiotherapy. In this work, MWCNTs filled with enriched ${ }^{152} \mathrm{SmCl}_{3}$ (Sm@MWCNTs) were sealed and irradiated, followed by surface functionalisation with an epidermal growth factor receptor (EGFR)-targeting antibody. Characterisation of functionalised Sm@MWCNTs was carried out using thermogravimetric analysis, gel electrophoresis and transmission electron microscopy. The organ biodistribution of the radioactive functionalised ${ }^{153}$ Sm@MWCNTs and therapeutic efficacy were studied in an experimental melanoma lung metastatic tumour model in mice after intravenous injection. Quantitative biodistribution analyses showed high accumulation of ${ }^{153} \mathrm{Sm} @$ MWCNT-Ab in lung. Significant tumour growth reduction was induced by both treatments of ${ }^{153} \mathrm{Sm} @$ MWCNTs functionalised with or without the antibody after a single intravenous injection. Although EGFR targeting showed no improvement in therapeutic efficacy, reduced spleen toxicity and normal haematological profiles were obtained for both functionalised derivatives. The current study demonstrated the possibility of performing chemical functionalisation and antibody conjugation on radioactive nanocapsules post-irradiation for the preparation of targeted radiopharmaceuticals.

\section{Introduction}

Radiotherapy is one of the mainstream cancer treatments, utilising high doses of ionizing radiation to destroy cancer cells. Currently, approximately $50 \%$ of patients with cancer will receive radiotherapy for the management of their disease either as the sole therapy, or as an adjuvant treatment in conjunction with chemotherapy, or in the form of palliative care in the case of metastases [1]. There are several ways to deliver radiotherapy, and radioisotope therapy (RIT) is one of the approaches where radioactive liquid is administered into the body by injection or ingestion. It is therefore considered as systemic radiotherapy, in contrast to external beam radiotherapy (EBRT), where radiation beams are directed from outside of the body onto the tumours. An obvious advantage of RIT over EBRT is that it is capable of tackling both localised solid tumours and disseminated metastases [2], while the latter is only applicable as a local therapy.

Many therapeutic radioisotopes have been employed in preclinical and clinical applications; the physicochemical properties of the radionuclides (e.g. $\alpha, \beta$ or Auger particle emitters), the type of cancers and stages, patient conditions and technical/facility feasibility etc. should all be considered 
when selecting the radiotherapeutic isotopes for cancer therapy [3]. Like chemotherapeutic drugs, one major challenge remains to maximise the accumulation in tumours while reducing the nonspecific uptake in healthy tissues that accounts for undesirable systemic toxicity. With this regard, a wide range of nanoparticles have been employed as carriers to deliver radioisotopes, aiming to improve the anti-tumour efficacy and reduce the side effects [2]. It is thought that nano-formulations can alter the fast elimination nature of most radioisotopes, load more or multiple radioisotopes onto a single particle, and also achieve tumour specific-targeting by surface functionalisation of nanoparticles with ligands.

Using chelators such as diethylenetriaminepentaacetic acid (DTPA) and 1,4,7,10tetraazacyclododecane-1,4,7,10-tetraacetic acid (DOTA) is a common strategy to label nanoparticles with radioisotopes [2, 4]. For example, Werner et al. have formulated folate-targeted polyethylene glycol-poly(lactic-co-glycolic acid) (PEG-PLGA) nanoparticles loaded with paclitaxel and labelled with a $\beta$ emitter ${ }^{90} \mathrm{Y}$ [5]. Using an ovarian peritoneal metastasis model, the mice receiving combined chemoradiotherapy showed longer survival than the ones given monotherapy. Another study conducted by Lin et al. developed a therapeutic and diagnostic PEGylated liposome labelled with ${ }^{188} \operatorname{Re}$ emitting both $\beta$ and $\gamma$ particles. Uptake of ${ }^{188}$ Re-liposomes in tumours was imaged by SPECT/CT and the treatment improved the median survival time in an orthotopic lung tumour model [6]. The radiolabelling yields are generally high in the chelator-mediated strategy; however, thermodynamic and kinetic stability can be compromised in vivo [7].

Researchers have explored the concept of chelator-free radioactive nanoparticles, particularly for inorganic nanoparticles. Examples of intrinsic radiolabelling include ${ }^{64} \mathrm{Cu}$ sulfide nanoparticles in which the radioisotope was part of the building components of the nanoparticles [8], and mesoporous silica nanoparticles (MSNs) that immobilised a wide range of radiometals thanks to their oxygen-rich matrix [9]. Another approach is to generate radioactive nanoparticles by neutron activation of stable isotope. ${ }^{165}$ Ho-doped MSNs were activated by neutron irradiation, and the resulting ${ }^{166} \mathrm{Ho}$-labelled MSN successfully improved the survival of ovarian tumour-bearing mice [10]. Our team has pioneered the work to create radioactive carbon nanocapsules by neutron activation of the encapsulated metals for cancer radiotherapy [11]. Non-radioactive ${ }^{152} \mathrm{SmCl}_{3}$ was filled and sealed into single-walled and multi-walled carbon nanotubes (SWCNTs and MWCNTs), which were then converted to ${ }^{153} \mathrm{Sm}$ via neutron activation. High specific radioactivity was obtained in the resultant ${ }^{153} \mathrm{Sm} @$ MWCNTs, which is sufficient for SPECT/CT imaging. Furthermore, the conjugate has 
shown to be therapeutically effective in delaying growth of metastatic lung tumours after single intravenous injection [11].

The present work took it further developing an antibody (Ab)-functionalised MWCNTs packaging radiotherapeutic ${ }^{153} \mathrm{Sm}$ for specific tumour targeting. Cetuximab, the antibody against epidermal growth factor receptor (EGFR), was covalently conjugated to neutron-activated ${ }^{153} \mathrm{Sm} @ \mathrm{MWCNTs}$ [12]. Characterisation of functionalised Sm@MWCNTs was carried out using thermogravimetric analysis (TGA), gel electrophoresis and transmission electron microscopy (TEM). Taking advantage of the fact that ${ }^{153} \mathrm{Sm}$ emits both $\gamma$ photons $(103 \mathrm{keV}$ ) and $\beta$ particles (maximum $810 \mathrm{keV}$ ), pharmacokinetics and organ biodistribution of ${ }^{153} \mathrm{Sm} @$ MWCNT-Ab were assessed quantitatively by $\gamma$ counting. Using an experimental lung metastatic melanoma model, the therapeutic efficacy was evaluated following intravenous administration.

\section{Experimental section}

\subsection{Materials}

The chemicals and solvents were obtained from commercial suppliers and used without further purification. Chemical vapour deposition (CVD) grown MWCNTs (Elicarb® MWNT) were provided by Thomas Swan \& Co. Ltd (UK) as a solid powder. Enriched samarium-152(III) oxide ${ }^{152} \mathrm{Sm}_{2} \mathrm{O}_{3}$ was provided by Eurisotop (France). ICP-MS analysis of the starting ${ }^{152} \mathrm{Sm}_{2} \mathrm{O}_{3}$ material, dissolved in diluted hydrochloric acid $\left(10 \mathrm{mg} \mathrm{Sm} \cdot \mathrm{L}^{-1}\right)$, shows the presence of $98.38 \%$ of the 152 -samarium isotope. Cetuximab was obtained from Guy's Hospital (UK) as pharmaceutical formulation Erbitux® (Merck KGaA, Germany) at a concentration of $5 \mathrm{mg} \cdot \mathrm{mL}^{-1}$. The solvents used for synthesis were analytical grade. When anhydrous conditions were required, high quality commercial dry solvents were used. Water was purified using a Millipore filter system MilliQ®. When stated, suspensions were sonicated in a water bath $(20 \mathrm{~W}, 40 \mathrm{kHz})$. For filtration of CNTs, polycarbonate and polytetrafluoroethylene (PTFE) membranes from Millipore were employed. If not differently specified, dialysis of CNT compounds was carried out employing membranes with MWCO 1200014000 Da purchased from Spectrum Laboratories, Inc. Mini-dialysis and buffer exchange were performed in Slide-A-Lyzer dialysis tubes (10000 MWCO) from Thermo Scientific. Centrifugation was performed either using an Eppendorf 5804 R apparatus, Eppendorf 5810R, A-4-81 rotor or a Beckman Avanti J-25 centrifuge equipped with JS-7.5 rotor. The BCA protein assay kit was purchased by Thermo Fisher Scientific. Tris-Glycine gels (4-20\%) were purchased from Bio-Rad Laboratories (USA). RPMI-1640 medium, penicillin/streptomycin, trypsin/EDTA, phosphate buffered saline (PBS) and other cell culture supplements were obtained from Gibco (Thermo Fisher 
Scientific, UK). Fetal bovine serum (FBS) was purchased from First Link UK Ltd. Puromycin, thiazolyl blue tetrazolium bromide (MTT reagent), Laemmli buffer, $\beta$-mercaptoethanol, Coomassie blue and polyethylenimine (PEI) were acquired from Sigma-Aldrich (UK). D-luciferin potassium salt was purchased from Perkin-Elmer (UK).

\subsection{Preparation of Sm@MWCNTs}

As-received MWCNTs were initially treated with a mixture of sulphuric/nitric acids followed by steam, using a previously reported protocol [13]. This treatment resulted in purified samples of openended short MWCNTs. We employed the same batch of MWCNTs used in our previous study which resulted in a median length of ca. $330 \mathrm{~nm}$ [11]. About $200 \mathrm{mg}$ of finely ground MWCNTs were placed inside a round bottom flask containing a mixture of sulphuric $(18 \mathrm{M})$ and nitric $(15.8 \mathrm{M})$ acid in a 3:1 ratio. The MWCNTs were sonicated in the acid mixture for $24 \mathrm{~h}$. After the treatment, the solution was diluted with water and filtered through a $0.2 \mu \mathrm{m}$ polycarbonate membrane. The sample was then rinsed with water until the $\mathrm{pH}$ of the filtrate was neutral, collected and left drying at $80^{\circ} \mathrm{C}$ overnight. The solid powder was then spread on a sample holder (silica tube, $\varnothing=4 \mathrm{~cm}$ ) which was placed inside a larger alumina tube $(\varnothing=5 \mathrm{~cm})$ centred in the middle of a tubular furnace. The MWCNT sample was treated with argon and steam. Argon was purged through the system for $2 \mathrm{~h}$ before introducing steam, to ensure the complete removal of oxygen from the system. Steam was next introduced by bubbling argon through hot water and the furnace annealed up to $900{ }^{\circ} \mathrm{C}$ (at a rate of $300{ }^{\circ} \mathrm{C} / \mathrm{min}$ ). The temperature of $900{ }^{\circ} \mathrm{C}$ was held for $1 \mathrm{~h}$. After the steam treatment, the MWCNTs were collected and treated overnight using hydrochloric acid $(6 \mathrm{M})$ at $110^{\circ} \mathrm{C}$. The solution was filtered through a polycarbonate membrane $(0.2 \mu \mathrm{m}$ pore size $)$ and dried overnight at $80^{\circ} \mathrm{C}$. TGA was performed using platinum pans on a TA Q-5000-IR TGA instrument with the following parameters: heating up to 900 ${ }^{\circ} \mathrm{C}$ at $10^{\circ} \mathrm{C} \cdot \mathrm{min}^{-1}$, air gas flow rate of $25 \mathrm{~mL} \cdot \mathrm{min}^{-1}$ and about $3 \mathrm{mg}$ of sample.

Filling MWCNTs with cold enriched ${ }^{152} \mathrm{SmCl}_{3}$ was performed following a previously reported filling method for non-enriched material [14]. Enriched ${ }^{152} \mathrm{Sm}_{2} \mathrm{O}_{3}$ powder was dissolved in a diluted $\mathrm{HCl}$ solution, followed by slow solvent evaporation at about $90{ }^{\circ} \mathrm{C}$. The sample was dehydrated at $240{ }^{\circ} \mathrm{C}$ under vacuum and placed in an argon-filled glovebox. The resulting dry ${ }^{152} \mathrm{SmCl}_{3}$ was then mixed with MWCNTs (about $100 \mathrm{mg}$ per experiment) in a 10:1 weight ratio, well ground and placed in several silica tubes $(\varnothing=1 \mathrm{~cm})$. These tubes were sealed under vacuum and placed in a tubular furnace, where an annealing step was carried out $\left(1200^{\circ} \mathrm{C}\right.$ for $\left.12 \mathrm{~h}\right)$. The annealing allowed the encapsulation of the metal halide into MWCNTs and ensured the end-closure of nanotubes, creating thus the carbon nanocapsules [15]. Samples were collected from silica ampoules and mixed together. In order to 
remove the non-encapsulated $\mathrm{SmCl}_{3}$, external to the CNT walls, the samples were washed using an acidic solution [16]. The sample was initially soaked in acidic water $(200 \mathrm{~mL}$ of water mixed with 5 $\mathrm{mL}$ of $\mathrm{HCl})$ and filtered on a polycarbonate membrane $(0.2 \mu \mathrm{m})$. The sample was then washed for 3 times in $200 \mathrm{~mL}$ of hot acidic water $\left(80^{\circ} \mathrm{C}, 24 \mathrm{~h}\right.$ per wash, constant stirring), with filtration inbetween. Finally, the sample was washed one more time, using water (without acid) and same washing conditions, filtered and dried overnight at $80^{\circ} \mathrm{C}$.

Inductively coupled plasma mass spectrometry (ICP-MS) analysis was carried out at Cis Bio International using the PerkinElmer Sci EX ELAN ${ }^{\circledR}$ DRC II system with a quadrupole collision cell. Samples for ICP-MS were microwave digested ( $800 \mathrm{~W}, 40 \mathrm{~min})$ in a 3:1 mixture of nitric:hydrogen peroxide (Suprapur ${ }^{\circledR}$ Merck KGaA, Germany). The contents of the reactor were then transferred to a polypropylene flask, followed by a series of washings with deionised water (ELGA Labwater PURELAB ${ }^{\circledR}$ Classic water purifying system; resistivity $18.2 \mathrm{M} \Omega / \mathrm{cm}$ ), and the volume was then made up to $25 \mathrm{~mL}$. HRTEM imaging was performed using a FEI Tecnai G2 F20 microscope operated at $200 \mathrm{kV}$.

\subsection{Synthesis of cold ${ }^{152} \mathrm{Sm} @ \mathrm{MWCNT}-\mathrm{NH}_{2}$}

Functionalisation of ${ }^{152} \mathrm{Sm} @$ MWCNTs was performed following the same approach used for cold non-enriched Sm@SWCNTs, previously reported [12]. In a dry Schlenk tube, $\mathrm{SmCl}_{3} @ \mathrm{MWCNTs}$ $(12 \mathrm{mg})$ were dispersed in dry NMP $(8 \mathrm{~mL})$ by sonicating for $15 \mathrm{~min}$ in a water bath under argon. A solution of a protected amino triethylene glycol terminated with an azide $(0.5 \mathrm{~g})$ in dry NMP $(5 \mathrm{~mL})$ was then added to the CNT dispersion and the mixture was heated at $190^{\circ} \mathrm{C}$ for $13 \mathrm{~h}$ under vigorous stirring and under argon (Scheme 1). The cooled mixture was then diluted with ethanol (15 $\mathrm{mL})$ and filtered over a PTFE membrane (Omnipore $\left.{ }^{\circledR} 0.1 \mu \mathrm{m}\right)$. The CNTs recovered on the filter were sonicated for $10 \mathrm{~min}$ in DMF (20 mL) to re-disperse them and wash them, and the dispersion was filtered again. Re-dispersion in fresh solvent, sonication and filtration were repeated with DMF (10 $\mathrm{mL})$ and twice with $\mathrm{MeOH}(2 \times 10 \mathrm{~mL})$.

An aliquot of phthalimide-functionalised ${ }^{152} \mathrm{Sm} @$ MWCNTs was kept for characterisation, while the remaining amount (ca. $11 \mathrm{mg}$ ) was dispersed in $\mathrm{EtOH}(10 \mathrm{~mL})$ by sonicating for $10 \mathrm{~min}$ and then treated with hydrazine hydrate $(1 \mathrm{~mL})$ for phthalimide cleavage. The dispersion was stirred at r.t. for $2 \mathrm{~h}$ and then filtered through a PTFE membrane (Omnipore ${ }^{\circledR} 0.1 \mu \mathrm{m}$ ). The membrane with the deposited CNTs was sonicated for $10 \mathrm{~min}$ in $\mathrm{EtOH}(5 \mathrm{~mL})$ and the dispersion was filtered again. Re- 
dispersion in fresh solvent, sonication and filtration were repeated twice with $\mathrm{MeOH}(2 \times 5 \mathrm{~mL})$ and finally with acetone $(5 \mathrm{~mL})$, yielding ${ }^{152} \mathrm{Sm} @ \mathrm{MWCNT}-\mathrm{NH}_{2}$.

\subsection{Synthesis of cold ${ }^{152} \mathrm{Sm} @$ MWCNT-Ab}

Cetuximab is available in commercial formulation Erbitux ${ }^{\circledR}$ in PBS buffer. Buffer exchange to 2-(Nmorpholino)ethanesulfonic acid (MES) buffer pH 7 was carried out using Slide-a-Lyzer Mini Device (MWCO 10000) to finally obtain a $2.25 \mathrm{mg} \cdot \mathrm{mL}^{-1}$ solution of Cetuximab in MES (concentration was verified by UV-Vis using a Varian Cary 5000 spectrophotometer). MES buffer $50 \mathrm{mM}$ was prepared by dissolving MES $(9.76 \mathrm{~g})$ in distilled deionised water $(800 \mathrm{~mL}) \cdot \mathrm{pH}$ was adjusted to 7 with $10 \mathrm{~N}$ $\mathrm{NaOH}$ before bringing the solution to $1 \mathrm{~L}$.

${ }^{152} \mathrm{Sm} @ \mathrm{MWCNT}-\mathrm{NH}_{2}$ (ca. $10 \mathrm{mg}$ ) were dispersed in DMF (1 mL) by sonicating for $15 \mathrm{~min}$. A solution of $N$-(3-dimethylaminopropyl)- $N$ '-ethylcarbodiimide hydrochloride $(\mathrm{EDC} \times \mathrm{HCl})(6 \mathrm{mM})$ and $N$-hydroxysulfosuccinimide sodium salt (sulfo-NHS, NHSS) $(4.4 \mathrm{mM})$ in MES (2 mL) was then added to the dispersion under sonication. After $5 \mathrm{~min}, 3 \mathrm{~mL}$ of Cetuximab $\left(2.25 \mathrm{mg} \cdot \mathrm{mL}^{-1}\right.$ in MES) were added and the mixture was gently stirred for $24 \mathrm{~h}$. Afterwards, the reaction mixture was homogenised by sonicating for $30 \mathrm{sec}$ and the ${ }^{152} \mathrm{Sm} @$ MWCNT-Ab conjugate was precipitated by centrifugation $\left(4500 \mathrm{rpm}, 10 \mathrm{~min}, 15^{\circ} \mathrm{C}\right.$ ). The supernatant was removed, the precipitated CNTs were re-dispersed in fresh PBS buffer $(10 \mathrm{~mL})$ by sonicating for $10 \mathrm{~min}$. Centrifugation, buffer removal and re-dispersion were repeated 3 times in order to thoroughly wash away the non-reacted antibody. After washing, the precipitated CNTs were re-dispersed in sterile PBS at a concentration of 2.43 $\mathrm{mg} \cdot \mathrm{mL}^{-1}$. An amount of $1.2 \mathrm{~mL}$ of this dispersion was stored at $4{ }^{\circ} \mathrm{C}$ for characterisation purposes, while the rest was used to dilute the hot ${ }^{153} \mathrm{Sm} @$ MWCNT-Ab conjugate prepared as described below after neutron irradiation for biodistribution studies.

\subsection{Neutron activation and synthesis of hot ${ }^{153} \mathrm{Sm} @ \mathrm{MWCNT}-\mathrm{Ab}$}

Neutron activation was used to produce radioactive ${ }^{153} \mathrm{Sm} @$ MWCNTs as described previously [11]. Irradiation was performed at a neutron flux of $1 \times 10^{4} \mathrm{n} \cdot \mathrm{cm}^{-2} \cdot \mathrm{s}^{-1}$ for $78 \mathrm{~h}$. Based on the filling yield of ${ }^{152} \mathrm{SmCl}_{3}$, the specific radioactivity was predicted to be $17.53 \mathrm{GBq}$ per mg of ${ }^{153} \mathrm{Sm} @ \mathrm{MWCNTs}$. The actual, final activity was $15.97 \mathrm{GBq}$ per mg of ${ }^{153} \mathrm{Sm} @ \mathrm{MWCNTs}$, which was consistent with expectations $[17,18]$. Following the same protocol described above for cold CNTs, $765 \mu \mathrm{L}$ of hot ${ }^{153} \mathrm{Sm} @$ MWCNTs $\left(<0.5 \mathrm{mg} \cdot \mathrm{mL}^{-1}, 807 \mathrm{MBq}\right)$ in DMF were mixed with $4 \mathrm{~mL}$ of a dispersion of cold ${ }^{152} \mathrm{Sm} @$ MWCNTs $(6 \mathrm{mg}$ ) in dry NMP, functionalised with the organic azide and deprotected with 
hydrazine hydrate to obtain ${ }^{153} \mathrm{Sm} @ \mathrm{MWCNT}-\mathrm{NH}_{2}$. Functionalisation of ${ }^{153} \mathrm{Sm} @ \mathrm{MWCNT}-\mathrm{NH}_{2}$ with Cetuximab was performed following the protocol above.

For in vivo studies, radioactive ${ }^{153} \mathrm{Sm} @ \mathrm{MWCNT}-\mathrm{NH}_{2}$ and ${ }^{153} \mathrm{Sm} @ \mathrm{MWCNT}-\mathrm{Ab}$ dispersions in PBS were mixed with different amounts of non-irradiated ${ }^{152} \mathrm{Sm} @ \mathrm{MWCNT}-\mathrm{NH}_{2}$ and ${ }^{152} \mathrm{Sm} @ \mathrm{MWCNT}$ $\mathrm{Ab}$, dispersions in PBS, respectively, to get the appropriate radioactivity suitable for the different in vivo studies. Each injection dose contained the same amount of Sm@MWCNTs or Sm@MWCNT$\mathrm{Ab}$ (mixtures of hot and cold materials, $200 \mu \mathrm{g} /$ mouse). The specific radioactivity used for the biodistribution or therapy studies will be reported in the experimental sections accordingly.

\subsection{Physicochemical characterisation: TGA, TEM and gel electrophoresis}

TGA was performed on a TGA1 (Mettler Toledo) apparatus from $30{ }^{\circ} \mathrm{C}$ to $900{ }^{\circ} \mathrm{C}$ with a ramp of 10 ${ }^{\circ} \mathrm{C} \cdot \mathrm{min}^{-1}$ under $\mathrm{N}_{2}$ using a flow rate of $50 \mathrm{~mL} \cdot \mathrm{min}^{-1}$ and platinum pans. For TGA of the ${ }^{152} \mathrm{Sm} @ \mathrm{MWCNT}-\mathrm{Ab}$ conjugate, an aliquot of a suspension in PBS was previously dialysed against deionised water to remove the buffer salts and lyophilised. For the loading estimation, values of weight loss were taken at $650{ }^{\circ} \mathrm{C}$.

The immunostaining experiments were performed following the protocol we reported in a previous work [12]. TEM analyses were performed on a Hitachi H7500 microscope (Tokyo, Japan) with an accelerating voltage of $80 \mathrm{kV}$, equipped with an AMT Hamamatsu camera (Tokyo, Japan).

Antibody conjugation was assessed by gel electrophoresis. The protein loading on ${ }^{152}$ Sm@MWCNT$\mathrm{Ab}$ was quantified by BCA protein assay performed according to the product protocol. Laemmli buffer was added to the samples for non-reducing conditions or Laemmli buffer supplemented with $5 \% \beta$-mercaptoethanol for reducing conditions. A protein ladder, Cetuximab and ${ }^{152} \mathrm{Sm} @ \mathrm{MWCNT}$ $\mathrm{Ab}$ were loaded into 4-20\% Tris-Glycine gels at similar protein concentration. The gel was run at a voltage of $150 \mathrm{~V}$ or $200 \mathrm{~V}$ for ca. $60 \mathrm{~min}$ (Mini-PROTEAN ${ }^{\circledR} \mathrm{TGX}^{\mathrm{TM}}$, Bio-Rad Laboratories, USA) and then stained with Coomassie blue overnight. After removing the staining solution, the gel was extensively washed with distilled water.

\subsection{Cell culture}

Mouse melanoma B16F10-Luc cells expressing luciferase were purchased from Perkin-Elmer (UK). For retroviral EGFR transduction, H29D human retroviral packaging cells (a gift from Prof J Maher, King's College London) were transfected with the EGFR plasmid (Addgene plasmid \#11011), which 
is packaged transiently in vesicular stomatitis virus (VSV) G pseudotyped particles [19]. PEI was used (10 $\mu \mathrm{L}$ of PEI $1 \mathrm{mM}$ to $5 \mu \mathrm{g}$ of plasmid) to transfect H29D cells. The cell culture media of $\mathrm{H} 29 \mathrm{D}$, containing the viral particles, was daily added to B16F10-Luc cells. The media was replaced after $24 \mathrm{~h}$ of incubation, and the cells were further cultured for $72 \mathrm{~h}$. Infected cells were then selected by culturing in puromycin-containing culture medium $\left(2 \mu \mathrm{g}-\mathrm{mL}^{-1}\right.$, cell specific sensitivity assessed by MTT assay). EGFR expression was confirmed by Western blotting. B16F10-Luc-EGFR cells were maintained in RPMI-1640 medium supplemented with $10 \% \mathrm{FBS}, 100 \mathrm{IU} \cdot \mathrm{mL}^{-1}$ penicillin and 100 $\mu \mathrm{g} \cdot \mathrm{mL}^{-1}$ streptomycin at $37^{\circ} \mathrm{C}$ in an incubator containing $5 \% \mathrm{CO}_{2}$.

\subsection{Animals}

All in vivo experiments were conducted under the authority of project and personal licences granted by the UK Home Office and the UKCCCR Guidelines (1998). Female C57BL/6 mice aged 6-8 weeks were purchased from Envigo (UK) and used for all in vivo studies. Mice were injected with B16F10Luc-EGFR cells via a tail vein $\left(5 \times 10^{5}\right.$ cells per injection per mouse) to establish pulmonary melanoma metastases.

\subsection{Pharmacokinetics and organ biodistribution of ${ }^{153} \mathrm{Sm} @ \mathrm{MWCNT}-\mathrm{Ab}$ by $\gamma$ counting}

To investigate the pharmacokinetics and organ biodistribution of ${ }^{153} \mathrm{Sm} @$ MWCNT-Ab, healthy and tumour-bearing C57BL/6 mice were injected with ${ }^{153} \mathrm{Sm} @$ MWCNT-Ab containing approximately $0.8 \mathrm{MBq}$ via a tail vein. Blood was sampled from a tail vein at $5 \mathrm{~min}, 10 \mathrm{~min}, 30 \mathrm{~min}, 1 \mathrm{~h}, 4 \mathrm{~h}$ or 24 $\mathrm{h}$ after injection. At $1 \mathrm{~h}, 4 \mathrm{~h}$ and $24 \mathrm{~h}$, major organs were excised and weighed. To assess the excretion profiles, animals were additionally housed individually in metabolic cages with free access to water but not food. Urine and faeces were collected over $24 \mathrm{~h}$ after injection. The radioactivity of the above samples (i.e. tissues, blood, urine and faeces) was measured by $\gamma$-counting (LKB Wallac 1282 Compugamma, PerkinElmer) and the results were expressed as percentage injection dose per sample (\% ID) or per g of sample (\% ID/g).

\subsection{Invivo ${ }^{153} \mathrm{Sm} @$ MWCNT and ${ }^{153} \mathrm{Sm} @$ MWCNT-Ab radiotherapy studies}

Following tumour inoculation, in vivo quantitative bioluminescence imaging was performed twice a week to monitor the tumour growth (IVIS Lumina III, Perkin-Elmer, UK). Mice under anaesthesia were subcutaneously injected with luciferin at $150 \mathrm{mg} \cdot \mathrm{kg}^{-1}$ and imaged $10 \mathrm{~min}$ after injection. Bioluminescence signals from regions of interests were measured using Living Image software (Perkin-Elmer, UK) and recorded as total flux (photons/sec). 
On Day 4 post-tumour inoculation, tumour-bearing mice were randomly divided into three groups $(n$ = 6-9): untreated, ${ }^{153} \mathrm{Sm} @ \mathrm{MWCNT}-\mathrm{NH}_{2}$ and ${ }^{153} \mathrm{Sm} @ \mathrm{MWCNT}-\mathrm{Ab}$. Mice assigned for treatments were intravenously injected with $200 \mu \mathrm{g}$ of ${ }^{153} \mathrm{Sm} @ \mathrm{CNT}$ dispersions containing approximately 15 MBq. Untreated mice were injected with saline as control. Tumour growth was monitored by bioluminescence imaging as described above. Mice were sacrificed on Day 17 post-tumour inoculation. Blood was sampled for haematological analysis performed by the Royal Veterinary College (London, UK). Major organs including lung, liver, spleen, heart and kidney were weighed and proceeded with histological examination. Harvested fixed organs were paraffin-embedded and sectioned for haematoxylin and eosin (H\&E) or Neutral Red staining according to standard histological protocols at the Royal Veterinary College (UK). All stained sections were analysed using a Leica DM 1000 LED microscope (Leica Microsystems, UK) coupled with a CCD digital camera (Qimaging, UK).

\subsection{Statistical analysis}

Quantitative data were expressed as mean \pm S.D. (standard deviation). Significant differences were examined using one-way ANOVA followed by Tukey's multiple comparison test.

\subsection{Dosimetry simulation}

The surviving fraction of cancer cells in targeted therapy can be estimated using the following model expressed in equation (1) [20]

$\mathrm{SF}(t)=\exp \left\{-\alpha r_{0}\left(\frac{m-k}{m k}+\frac{1}{m} e^{-m\left(t-t_{i}\right)}-\frac{1}{k} e^{-k\left(t-t_{i}\right)}\right)+\lambda\left(t-t_{0}\right)\right\}$

where $\alpha$ is the intrinsic radiosensitivity parameter for a given cell line, $r_{0}$ is the extrapolated initial dose-rate, $m$ is the effective uptake rate and $k$ the effective washout rate constants, $\lambda$ is the repopulation rate describing the exponential tumour growth, $t$ stands for time, $t_{0}$ is time of the first tumour size measurement (day 3 ), and $t_{i}$ is time of the radiopharmaceutical injection (day 4 ).

The non-irradiated mice tumour size data (day 3 to 13) were used to determine the repopulation rate $\lambda$ by the least square fit with function $N(t)=$ const $\exp (\lambda t)$. The fit yielded $\lambda=1.87 \cdot 10^{-2} \mathrm{~h}^{-1}$. Effective uptake and washout rates were estimated by fitting pharmacokinetic data using equation (2)

$\% I D(t)=\% I D_{0}\left(e^{-k t}-e^{-m t}\right)$ 
It should be noted that the \% ID data of lungs with tumour for hour 1 and 24 (lungs in Figure 5a) is not enough for the fit. Using the fact half-life of ${ }^{153} \mathrm{Sm}$ as 46.3 hours, the resulting parameters for simulation were $I D_{0}=80 \%, k=1.63 \cdot 10^{-2} \mathrm{~h}^{-1}, m=1.36 \mathrm{~h}^{-1}$. More kinetic data to fit would provide more reliable parameters.

The extrapolated initial dose rate, $r_{0}$, equals $\mathrm{A} \cdot \mathrm{ID}_{0} \cdot \mathrm{f}_{\mathrm{T}} \cdot \mathrm{S}$. A stands for administered activity $(\mathrm{A}=15$ $\mathrm{MBq}), \mathrm{ID}_{0}$ is $80 \%$ from previous paragraph, $f_{T}$ is mass fraction of the tumour in lungs $\left(f_{T}=\right.$ $\mathrm{M}_{\text {tumour }} /\left(\mathrm{M}_{\text {lungs }}+\mathrm{M}_{\text {tumour }}\right)$; using $0.05 \mathrm{~g}$ for tumour and $0.12 \mathrm{~g}$ for lungs, this yields $\left.f_{T}=0.294\right)$ and $\mathrm{S}$ is the absorbed radiation dose per radionuclide decay in the tumour $\left(\mathrm{Gy} \mathrm{Bq}^{-1} \mathrm{~s}^{-1}\right.$ ) (we do not take into account cross irradiation from other parts of the body). Assuming spherical tumour size of $0.05 \mathrm{~g}$ [21], $\mathrm{S}=5.7 \cdot 210^{-10} \mathrm{~Gy} \mathrm{~Bq}^{-1}$.

The last parameter left to deduce is $\alpha$, the intrinsic radiosensitivity parameter of the cells, determined empirically from cell survival data using the expression in equation (3)

$S F_{2}=\exp \left(-\alpha D-\beta D^{2}\right)$

where $\beta$ is the dose-rate dependent radionsensitivity parameter. Schiller et al. revealed cell survival for B16F10 after the dose of $2 \mathrm{~Gy}$ being $\mathrm{SF}_{2}=0.96$ [22]. This high value indicates the cell line is highly radioresistant. Three different $\alpha / \beta$ ratios were used from linear quadratic radiobiological model to deduce $\alpha[23,24]$. Applying $D=2$ Gy and $\alpha / \beta=1,2$ or 3 , equation (3) yields $\alpha=0.0068,0.0102$ and $0.0122 \mathrm{~Gy}^{-1}$, respectively.

\section{Results}

\subsection{Characterisation of the conjugates}

TGA on empty MWCNTs revealed $1.2 \mathrm{wt} \%$ solid residue which corresponds to oxidised inorganic species. This residue arises mainly from oxidised iron used as a catalyst in the CVD synthesis, and would correspond to 0.8 wt.\% Fe. ICP-MS analysis of ${ }^{152} \mathrm{Sm} @$ MWCNTs reveals a loading of 30.8 $\mathrm{w} \%{ }^{152} \mathrm{Sm}$. The high filling degree was confirmed by HRTEM imaging (Figure S1). The contrast offered by the filling material reveals the coexistence of fragments of nanowires and inorganic nanotubes, the latter resulting in the formation of tubular van der Waals heterostructures.

The ${ }^{152} \mathrm{Sm} @$ MWCNTs were functionalised by [2+1] cycloaddition of nitrenes generated in situ by thermolysis of an azide derivative bearing a triethylene glycol chain terminated with a phthalimide- 
protected amine (Scheme 1). The phthalimide-functionalised ${ }^{152} \mathrm{Sm} @$ MWCNTs were characterised by TGA, and the degree of functionalisation estimated from the weight loss comparison with pristine ${ }^{152} \mathrm{Sm} @$ MWCNTs was $13.5 \%$ (Figure 1), corresponding to a loading of $487 \mu \mathrm{mol} / \mathrm{g}$. After deprotection using hydrazine hydrate, the weight loss was slightly lower, as expected (Figure 1).

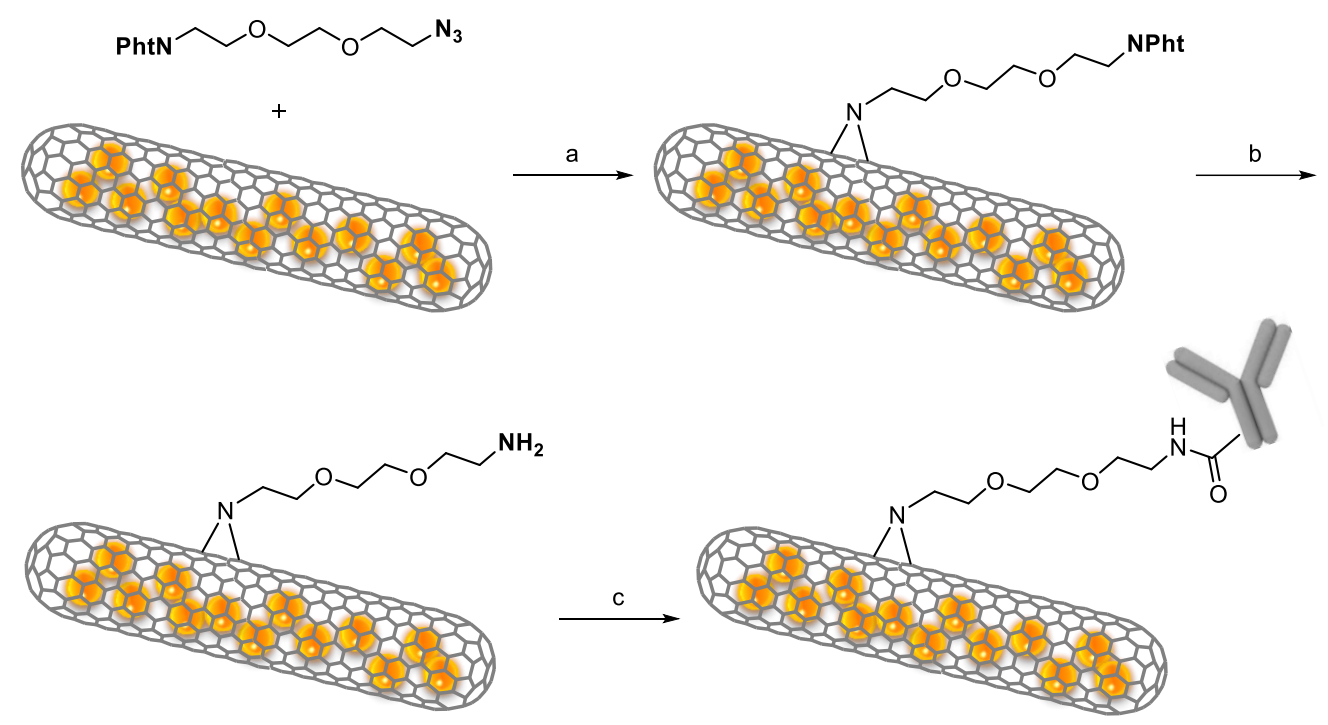

Scheme 1: Amine functionalisation and antibody conjugation of ${ }^{152} \mathrm{Sm@MWCNTs.} \mathrm{a)} \mathrm{Dry}$ $\mathrm{NMP}, 190^{\circ} \mathrm{C}, 13$ h; b) $\mathrm{NH}_{2}-\mathrm{NH}_{2}$, EtOH, r.t., 2 h; c) Cetuximab, EDCxHCl, NHSS, MES buffer pH 7.4, $24 \mathrm{~h}$.

Cetuximab was covalently conjugated onto the CNTs by amidation through activation of the $\mathrm{COOH}$ groups of the antibody using EDC and NHSS. The loading of antibody on ${ }^{152} \mathrm{Sm} @ \mathrm{MWCNT}-\mathrm{Ab}$ estimated by TGA was $220 \mathrm{mg} / \mathrm{g}$. The concentration of Ab loaded onto CNTs was further quantified by the BCA protein assay, a colorimetric assay commonly employed for the quantification of proteins, obtaining a loading of $173 \mathrm{mg} / \mathrm{g}$. This value is comparable to the loading obtained by TGA. 


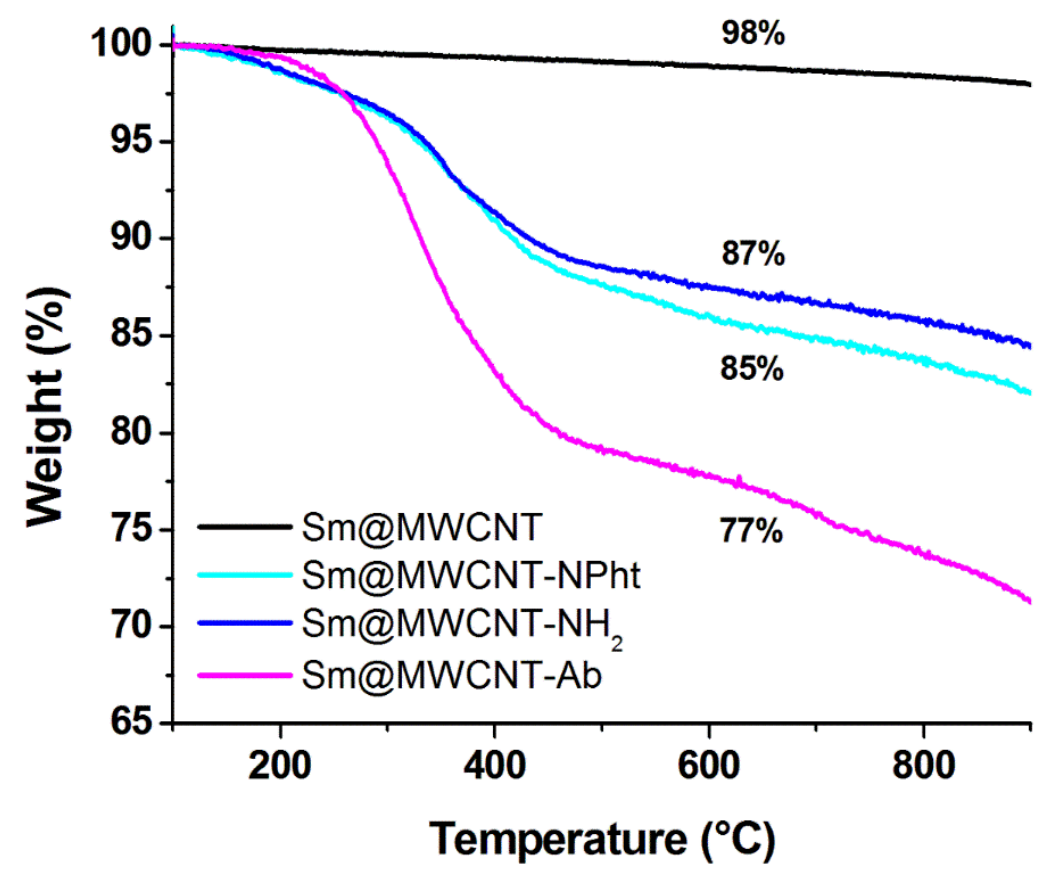

Figure 1: TGA curves of pristine ${ }^{152} \mathrm{Sm} @ M W C N T s$ (black) and the conjugates functionalised with the phthalimide-protected amine moieties (light blue), the amino groups (dark blue), and with the antibody (pink). The analyses were performed under $\mathrm{N}_{2}$ using a ramp of $10^{\circ} \mathrm{C} \cdot \mathrm{min}^{-1}$. The level of functionalisation was calculated from the weight loss values at $650{ }^{\circ} \mathrm{C}$.

The efficiency of the Ab immobilisation was then evaluated by gel electrophoresis under nonreducing and reducing conditions. As reported in Figure 2, in non-reducing conditions there is one main band at ca. $150 \mathrm{kDa}$ for Cetuximab, while there is no clear band corresponding to the antibody for the ${ }^{152} \mathrm{Sm} @$ MWCNT-Ab conjugate, and only a light shadow is visible (second and third lane, respectively). As CNT samples do not enter into the gel, this result suggests that most of the antibody present on the nanotubes was covalently bound. Under reducing conditions, the breakage of the antibody structure into heavy and light chains resulted in the appearance of two bands at ca. 25 and $50 \mathrm{kDa}$, respectively (fourth lane). In the case of the ${ }^{152} \mathrm{Sm} @ \mathrm{MWCNT}-\mathrm{Ab}$ conjugate, two main bands also appeared at ca. 25 and $50 \mathrm{kDa}$, corresponding to the detachment of the heavy and light chains, confirming the presence of the antibody onto the CNTs (fifth lane). 


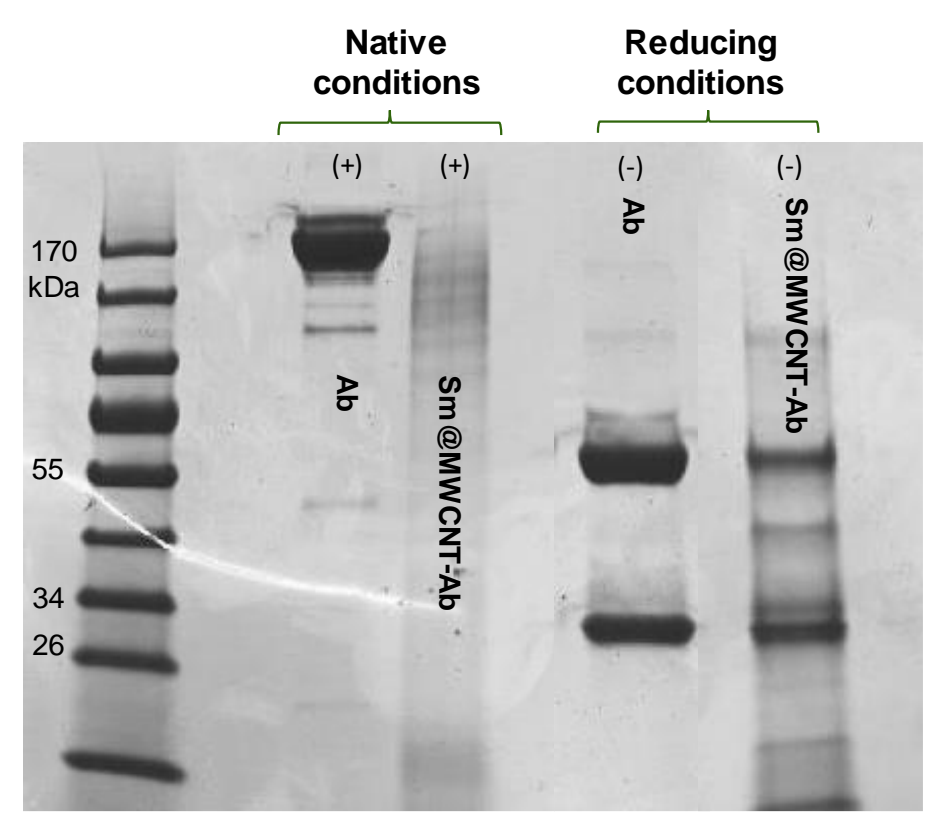

Figure 2: Gel electrophoresis of Cetuximab $(\mathrm{Ab})$ and ${ }^{152} \mathrm{Sm} @ \mathrm{MWCNT}-\mathrm{Ab}$ run under nonreducing (+) and reducing conditions (-) at $150 \mathrm{kV}$. The gel was stained with Coomassie blue. Protein ladder is shown in the first lane (size in $\mathrm{kDa}$ ).

The ${ }^{152}$ Sm@MWCNT-Ab conjugate was also characterised by TEM combined with immunostaining. The antibody-functionalised conjugate and ${ }^{152} \mathrm{Sm} @ \mathrm{MWCNT}-\mathrm{NH}_{2}$ as a control were stained with an anti-human IgG linked to colloidal gold nanoparticles (AuNPs) (15 nm diameter) able to recognise Cetuximab (human IgG) (Figure 3). For ${ }^{152} \mathrm{Sm} @ M W C N T-A b$ stained with the anti-human IgG/AuNP, a multitude of black dots were visible around the nanotube backbone, which corresponded to the AuNPs (Figure 3a-b). Almost no AuNPs were visible in the images of the control sample prepared by incubating the CNT precursor devoid of the antibody $\left({ }^{152} \mathrm{Sm} @ \mathrm{MWCNT}-\mathrm{NH}_{2}\right)$ (Figure $3 c-d)$ with the anti-human IgG/AuNP, proving that there was no unspecific adsorption of the IgG onto the CNTs. As an additional control, ${ }^{152} \mathrm{Sm} @$ MWCNT-Ab was separately stained with an antirabbit IgG/AuNP (15 nm), not specific towards human IgGs (Figure S2). ${ }^{152} \mathrm{Sm} @ \mathrm{MWCNT}-\mathrm{Ab}$ stained with the anti-rabbit IgG, did not show unspecific binding between the two antibodies. Overall, the immunostaining showed the specific binding of the anti-human IgG to Cetuximab on the CNTs, further confirming the conjugation of the antibody to the CNTs and allowing its localisation onto the nanotube backbone. It also proved that its ability to recognise an appropriate secondary antibody was preserved after covalent conjugation. 

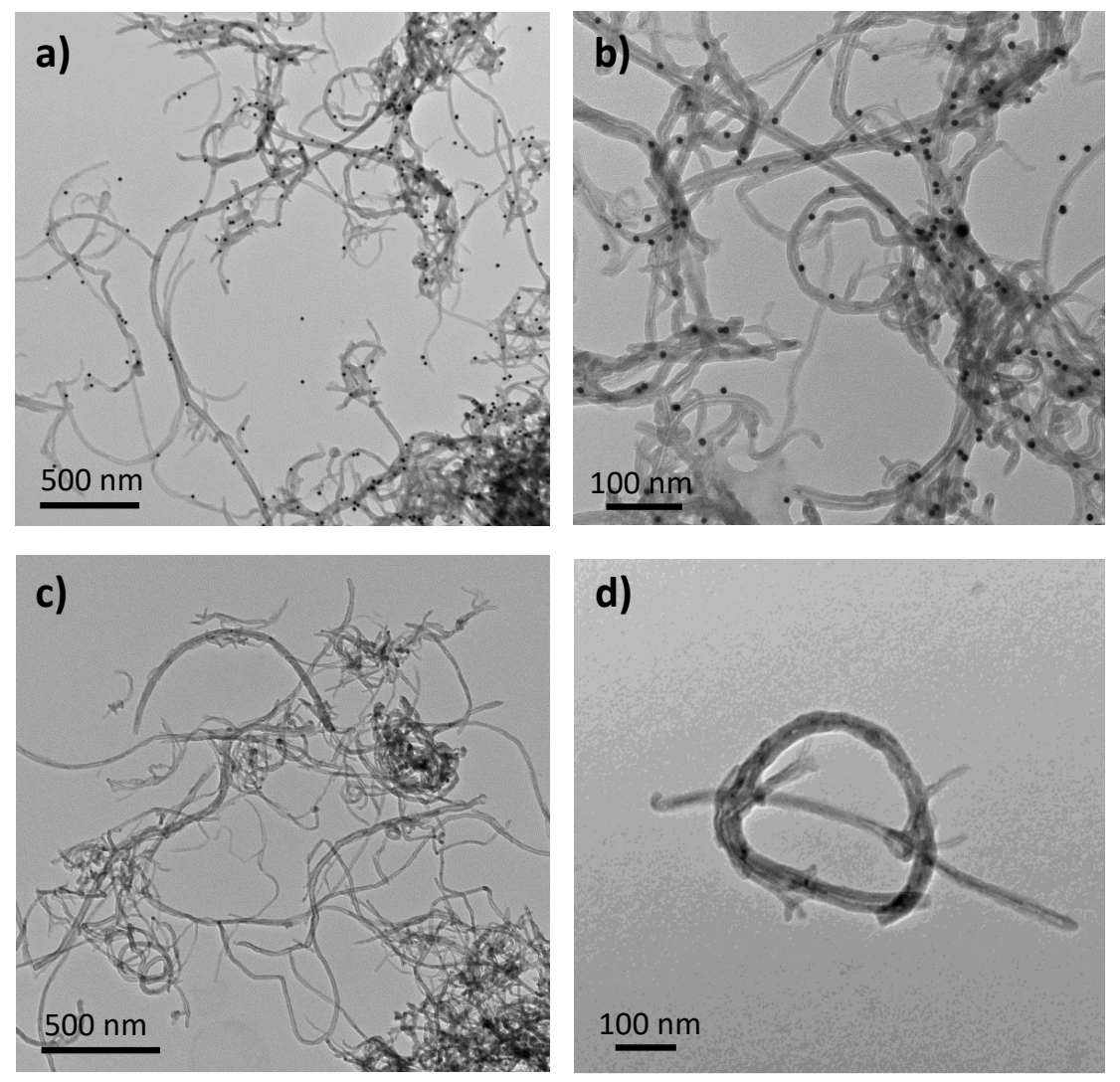

Figure 3: TEM images of ${ }^{152} \mathrm{Sm} @ \mathrm{MWCNT}-\mathrm{Ab}(\mathrm{a}-\mathrm{b})$ and ${ }^{152} \mathrm{Sm} @ \mathrm{MWCNT}-\mathrm{NH}_{2}$ (c-d) after staining with anti-human IgG/AuNP.

\subsection{Pharmacokinetics and organ biodistribution of ${ }^{153} \mathrm{Sm} @ \mathrm{MWCNT}-\mathrm{Ab}$ by $\gamma$ counting}

In vivo organ biodistribution of ${ }^{153} \mathrm{Sm} @ \mathrm{MWCNT}-\mathrm{Ab}$ in normal mice up to $24 \mathrm{~h}$ was assessed following intravenous injection. As shown in Figure 4, a fast clearance from the blood was observed in which less than $1 \%$ ID in the blood was detected at 30 min post-injection. The major accumulation was measured in lung ( 70 \% ID), followed by liver and spleen. Retention was observed in these organs with similar amount of uptake measured up to $24 \mathrm{~h}$. Negligible radioactivity was detected in urine and faece samples collected over $24 \mathrm{~h}$. Similar biodistribution profiles were found in experimental metastatic lung tumour-bearing C57BL/6 mice compared to normal C57BL/6 mice with prominent accumulation detected in lung, liver and spleen (Figure 5). 

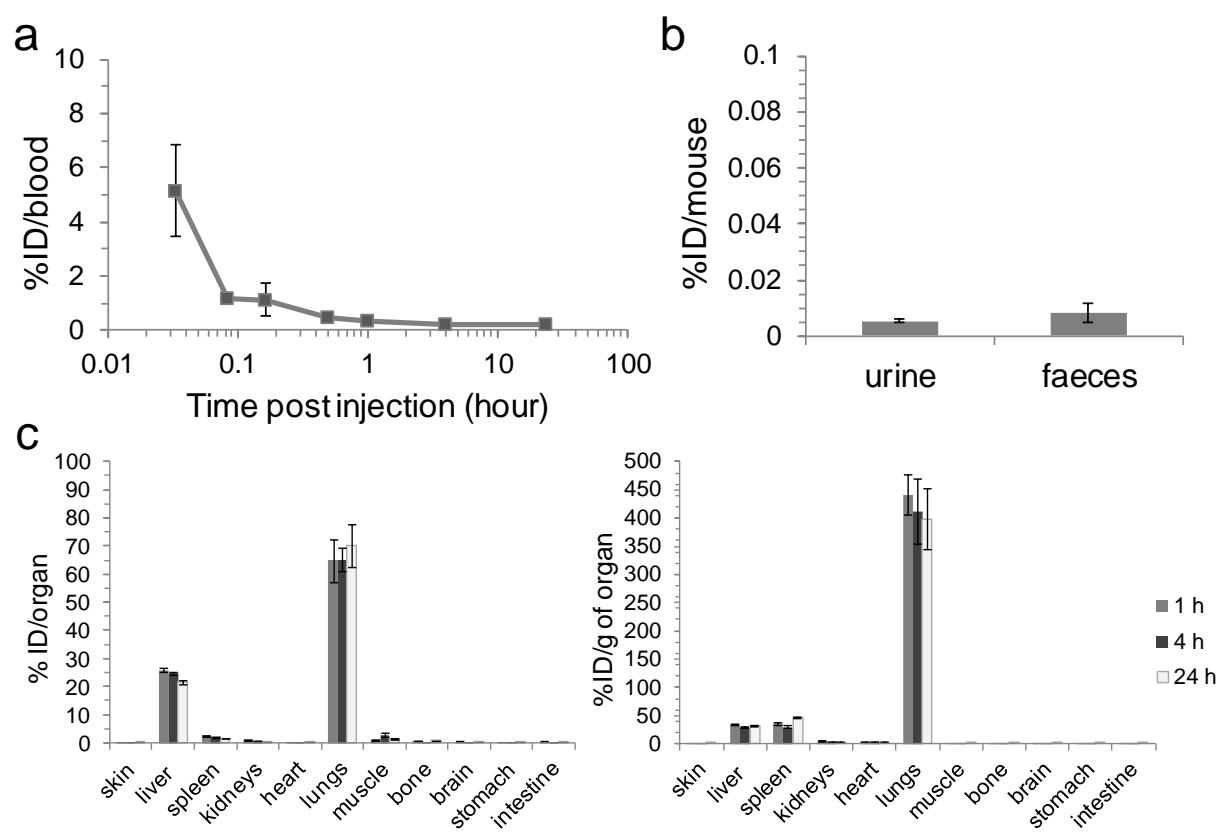

Figure 4: In vivo organ biodistribution of ${ }^{153} \mathrm{Sm} @$ MWCNT-Ab in healthy mice. (a) Blood profile (b) excretion profiles (c) organ biodistribution profiles. C57BL/6 mice were i.v. injected with $200 \mu \mathrm{g}$ of ${ }^{153} \mathrm{Sm} @$ MWCNTs containing 1 MBq. In excretion studies, mice were housed individually in metabolic cages for $24 \mathrm{~h}$ immediately after injection. The radioactivity in blood, major organs sampled at specified time points and urine/faeces collected at $24 \mathrm{~h}$ post-injection, were measured by $\gamma$ counting. All the results are expressed as mean \pm S.D. $(n=3)$. The biodistribution in organs are presented as \%ID per organ (c, left) or per g of organ (c, right).

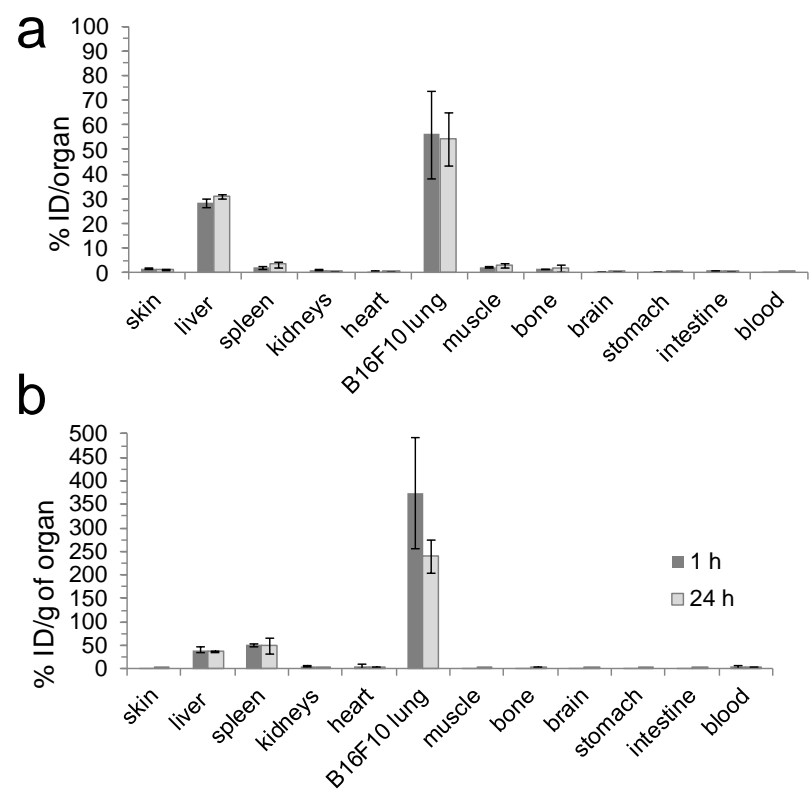

Figure 5: In vivo organ biodistribution of ${ }^{153} \mathrm{Sm} @$ MWCNT-Ab in experimental metastatic lung tumour mice model at $1 \mathrm{~h}$ and $24 \mathrm{~h}$ post-injection. (a) \% ID per organ (b) \%ID per g of organ. 
B16F10-Luc tumour-bearing C57BL/6 mice were i.v. injected with $200 \mu \mathrm{g}$ of ${ }^{153} \mathrm{Sm} @ \mathrm{MWCNTs}$ containing $\sim 1 \mathrm{MBq}$. The radioactivity in blood and major organs were sampled at 1 and $24 \mathrm{~h}$ postinjection and measured by $\gamma$ counting. All the results are expressed as mean \pm S.D. $(n=3)$.

\subsection{Radiotherapy of ${ }^{153} \mathrm{Sm} @ M W C N T-\mathrm{NH}_{2}$ and ${ }^{153} \mathrm{Sm} @ \mathrm{MWCNT}-\mathrm{Ab}$ in B16F10-Luc-EGFR melanoma lung model}

B16F10-Luc-EGFR melanoma lung metastasis was the choice of cancer model to assess the radiotherapeutic efficacy of ${ }^{153} \mathrm{Sm} @ \mathrm{MWCNT}-\mathrm{Ab}$ since the highest uptake was found in lung. The results showed that both ${ }^{153} \mathrm{Sm} @ \mathrm{MWCNT}-\mathrm{NH}_{2}$ and ${ }^{153} \mathrm{Sm} @ \mathrm{MWCNT}-\mathrm{Ab}$ containing $15 \mathrm{MBq}$ of radioactivity (200 $\mu \mathrm{g}$ of CNTs per mouse) significantly inhibited the tumour growth in lung after single dose injection (Figure 6). As clearly shown in the representative bioluminescence images taken on Day 13 and 17 post-tumour inoculation (Figure 6a), lower signals were detected in mice treated with ${ }^{153} \mathrm{Sm} @$ MWCNT-NH 2 or ${ }^{153} \mathrm{Sm} @$ MWCNT-Ab compared to untreated mice, indicating the reduction in tumour growth after radiotherapy. Figure $6 \mathrm{~b}$ shows quantitative bioluminescence imaging analysis on tumour growth over the therapy period. The injection of ${ }^{153} \mathrm{Sm} @ \mathrm{MWCNT}-\mathrm{NH}_{2}$ or ${ }^{153} \mathrm{Sm} @$ MWCNT-Ab was done on Day 4 post-tumour inoculation and significant tumour growth inhibition was detected on Day 10 until the end of the study on Day $17(p<0.01)$. Conjugation of antiEGFR antibody however did not seem to enhance the therapeutic effect further as the tumour sizes of mice treated with ${ }^{153} \mathrm{Sm} @$ MWCNT-NH 2 and ${ }^{153} \mathrm{Sm} @$ MWCNT-Ab were not significantly different from each other.

As shown in Figure 6c, reduced number of tumour nodules can be visualised in the excised lung tissues from mice that received radiotherapy compared to untreated mice (Day 17). This resulted in lower lung weight in treated mice than the untreated mice $(p<0.001)$. Histological examination on lung tissues further confirmed the macroscopic observation of the high therapeutic efficacy of ${ }^{153} \mathrm{Sm} @ \mathrm{MWCNT}-\mathrm{NH}_{2}$ and ${ }^{153} \mathrm{Sm} @ \mathrm{MWCNT}-\mathrm{Ab}$ treatments (Figure 7). High density of melanoma cells had invaded most of the lung tissue in the untreated mice without the normal presence of alveoli and bronchioles. In contrast, small and few tumour nodules were observed in the lungs of mice that received radiotherapy with abundant alveoli and bronchioles (Figure 7, left panel). Selected zoom-in images of tumour and non-tumour areas are shown in the middle and right panels. Some necrotic tumour cells can be found in treated lungs. It is difficult to identify CNTs in the lung tissues due to the melanin pigmentation of melanoma. 


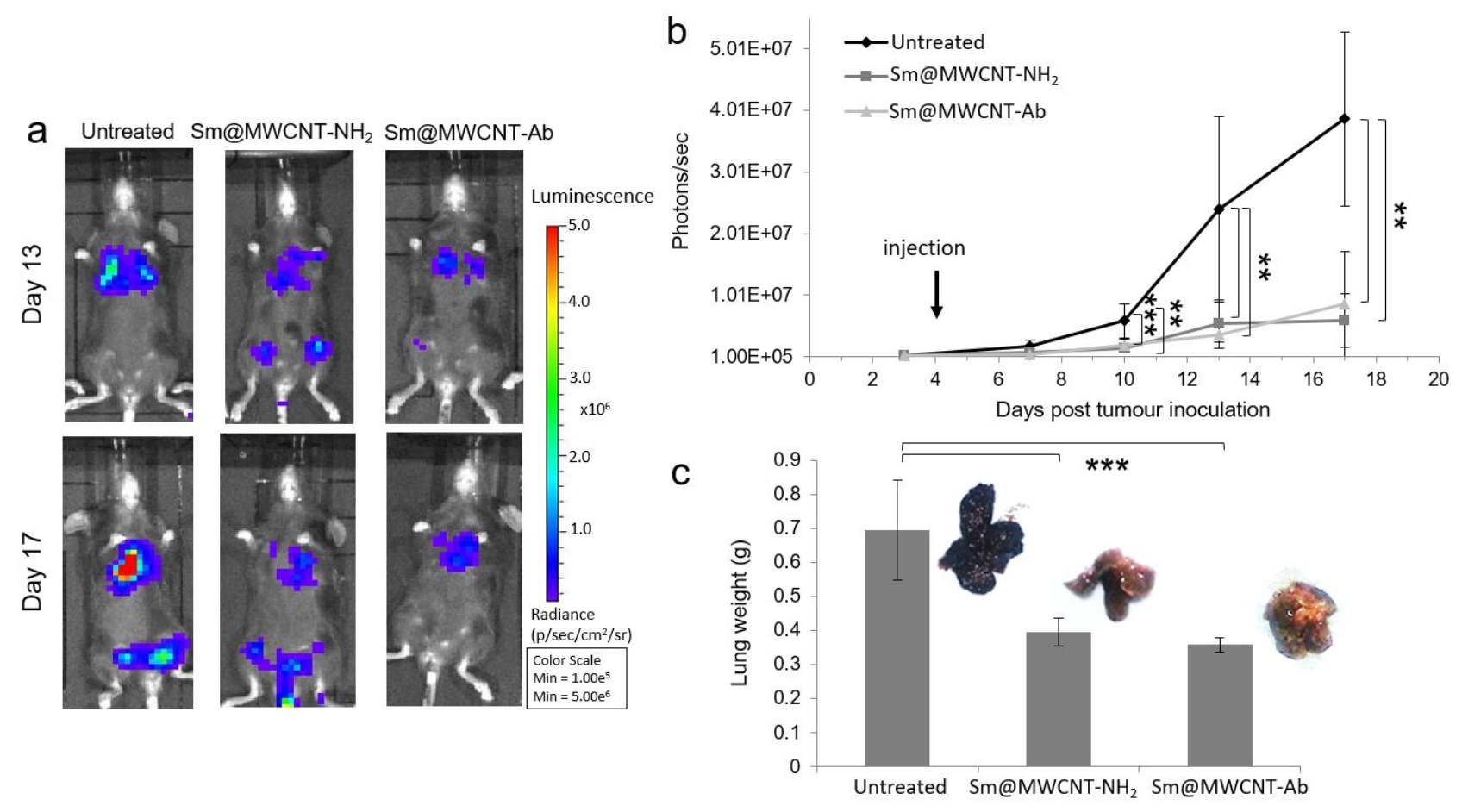

Figure 6: In vivo radiotherapy studies of ${ }^{153} \mathrm{Sm} @ M W C N T-N H_{2}$ and ${ }^{153} \mathrm{Sm} @ M W C N T-A b$ in experimental metastatic lung tumour-bearing mice. (a) Representative whole-body images of untreated, ${ }^{153} \mathrm{Sm} @$ MWCNT-NH 2 and ${ }^{153} \mathrm{Sm} @ M W C N T-A b$ treated mice captured on Day 13 and Day 17 post-tumour inoculation. Bioluminescence signals correspond to luciferase expressing B16F10Luc-EGFR cells in the lung. (b) Tumour growth monitoring over the therapy time course. (c) Average lung weight measured on Day 17 post-tumour inoculation, the experimental endpoint. EGFRexpressing B16F10 metastatic lung tumour-bearing C57BL/6 mice received a single dose i.v. injection of ${ }^{153} \mathrm{Sm}-\mathrm{MWCNT}-\mathrm{NH}_{2}$ or ${ }^{153} \mathrm{Sm} @ M W C N T-A b(15 \mathrm{MBq}, 200 \mu \mathrm{g})$ on Day 4 post-tumour inoculation. Results are presented as mean \pm S.D. $(n=6-9)$. Significant differences were examined using one-way ANOVA following by Tukey's multiple comparison test $(* * p<0.01, * * * p<0.001)$. 


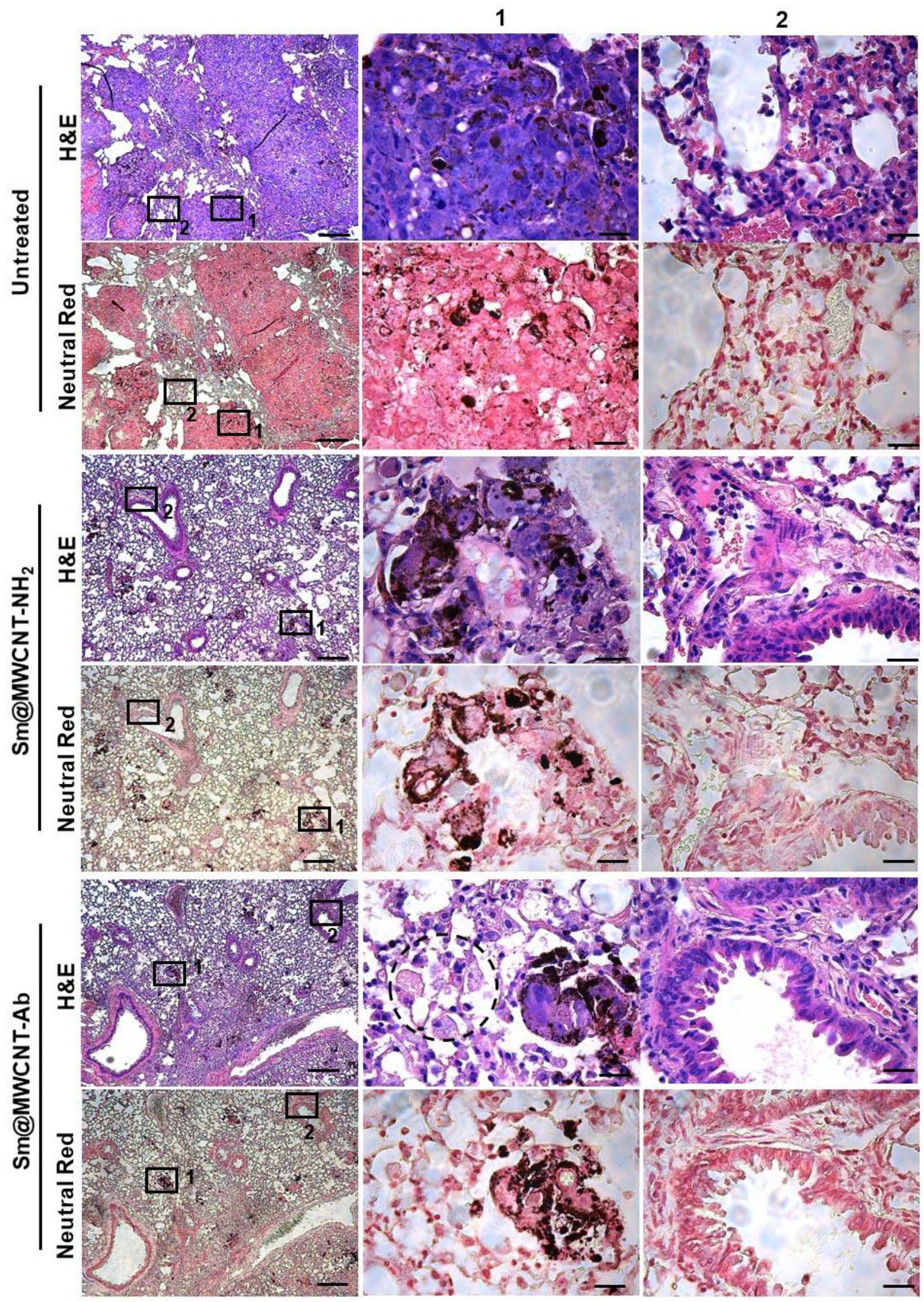


Figure 7: Histological examination of lung tissues post ${ }^{153} \mathrm{Sm} @ \mathrm{MWCNT}-\mathrm{NH}_{2}$ and ${ }^{153}$ Sm@MWCNT-Ab radiotherapy. EGFR-expressing B16F10 lung metastasis-bearing C57BL/6 mice were i.v injected with $\sim 15 \mathrm{MBq}$ of ${ }^{153} \mathrm{Sm} @ \mathrm{MWCNT}-\mathrm{NH}_{2}$ or ${ }^{153} \mathrm{Sm} @ \mathrm{MWCNT}-\mathrm{Ab}(200 \mu \mathrm{g})$ on Day 4 post-tumour inoculation. Lung tissues from the above two treated groups and the untreated group were harvested on Day 17 and proceeded with histological examination. H\&E (top panel) and Neutral Red (bottom panel) staining images are shown to the left (scale bars: $200 \mu \mathrm{m}$ ). The high magnification images of tumour (areas 1) and non-tumour (areas 2) lung tissues are shown in the middle and to the right (scale bars: $6 \mu \mathrm{m}$ for zoomed-in images, areas 1 and 2). The dash circle indicates some necrotic tumour cells.

\subsection{Overall toxicity assessment after radiotherapy}

Toxicity and adverse effects of ${ }^{153} \mathrm{Sm} @ \mathrm{MWCNT}-\mathrm{NH}_{2}$ and ${ }^{153} \mathrm{Sm} @ \mathrm{MWCNT}-\mathrm{Ab}$ radiotherapy were assessed by monitoring the whole body weight changes post-therapy, and measuring the vital organ weight and analysing haematological profiles at the end of the study (Figure 8). No significant difference was found between the groups expressed as $\%$ whole body weight change in reference to Day 0 before tumour inoculation (Figure 8a). Significant body weight loss (20\%) was measured on Day 13 for all groups which was likely to be a result of tumour progression, not due to radiotherapy. Apart from lung tissues containing tumours, the other major organs did not display significant weight loss in all untreated and treated mice (Figure 8b). As we observed some toxicity in spleen using the compound without functionalisation previously [11], haematological analysis was performed for naïve mice (bearing no tumours), untreated tumour-bearing mice and mice that received radiotherapy. Decreased white blood cell counts were measured in radiotherapy mice compared to naïve or untreated tumour-bearing mice although the differences were not significant $(p>0.05$, data not shown). As shown in Figure 8c, the \% of lymphocyte decreased from $84 \pm 4.2 \%$ in naïve mice to $60.3 \pm 9.2 \%(\mathrm{p}=0.03)$ in untreated tumour-bearing mice. In contrast, the $\%$ of neutrophil increased from $15.7 \pm 4 \%$ in naïve mice to $35.3 \pm 10.7 \%(\mathrm{p}=0.04)$ in untreated tumour-bearing mice. Nevertheless, no significant differences in the $\%$ of various white blood cell population were detected among the tumour-bearing mice with or without treatment. The results indicated that the changes in the $\%$ of lymphocytes and neutrophils were due to the presence of the tumour, and not directly associated with the radiotherapy.

Histological analysis was carried out on H\&E stained major organs excised post radiotherapy. As shown in Figure S3, no major histologic changes were observed in heart, liver, spleen and kidney. From the adjacent sections stained with Neutral Red (bottom panel), the presence of CNTs can be 
observed in liver and spleen of the mice that received treatment. This is in line with the organ biodistribution data obtained by gamma counting that the uptake of CNTs were detected in liver and spleen, in addition to lung. Interestingly, CNTs accumulated more in the red pulp of spleen which is made up of many types of blood cells including phagocytic cells, compared to the white pulp which mainly contains lymphocytes.
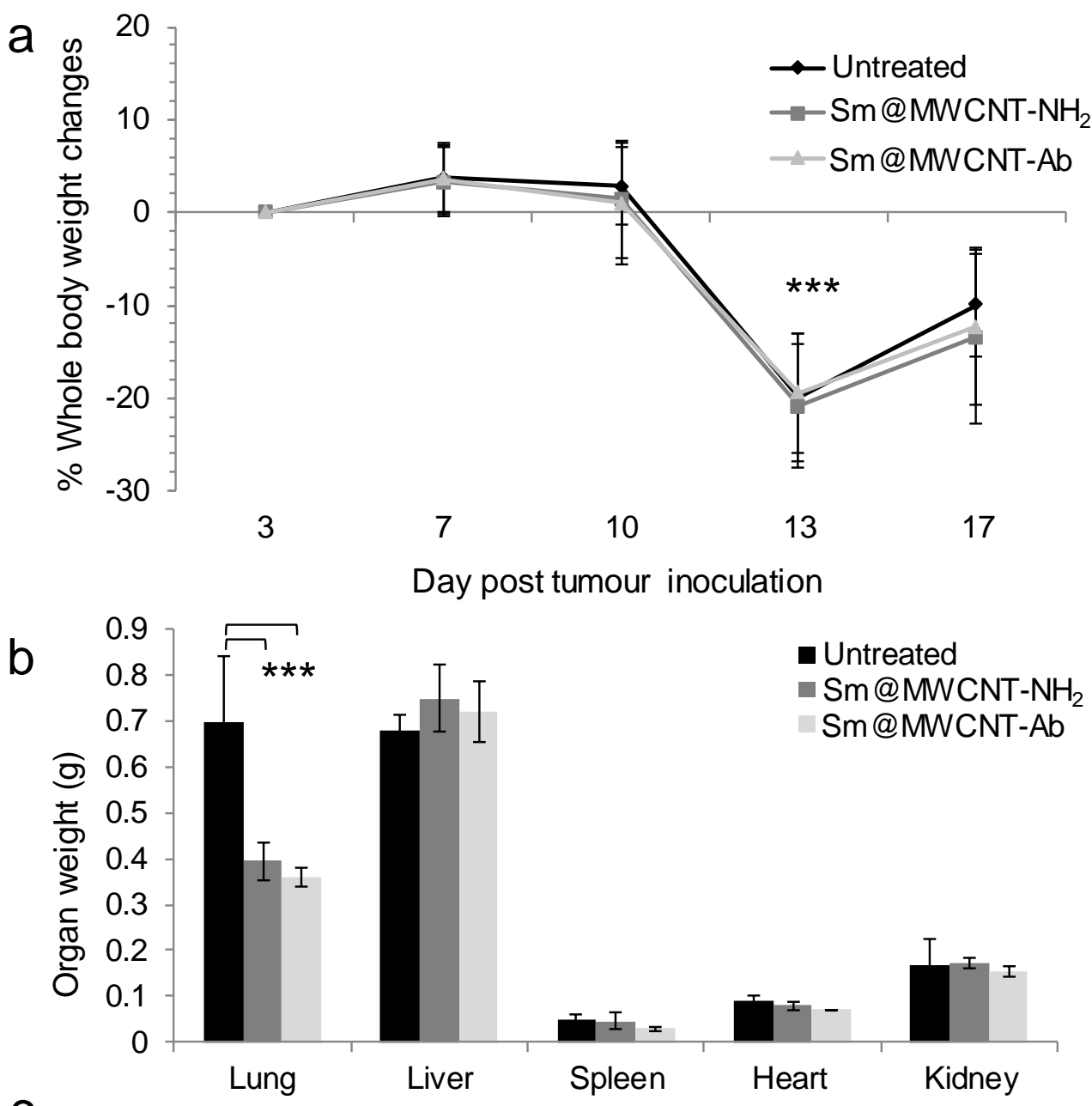

C

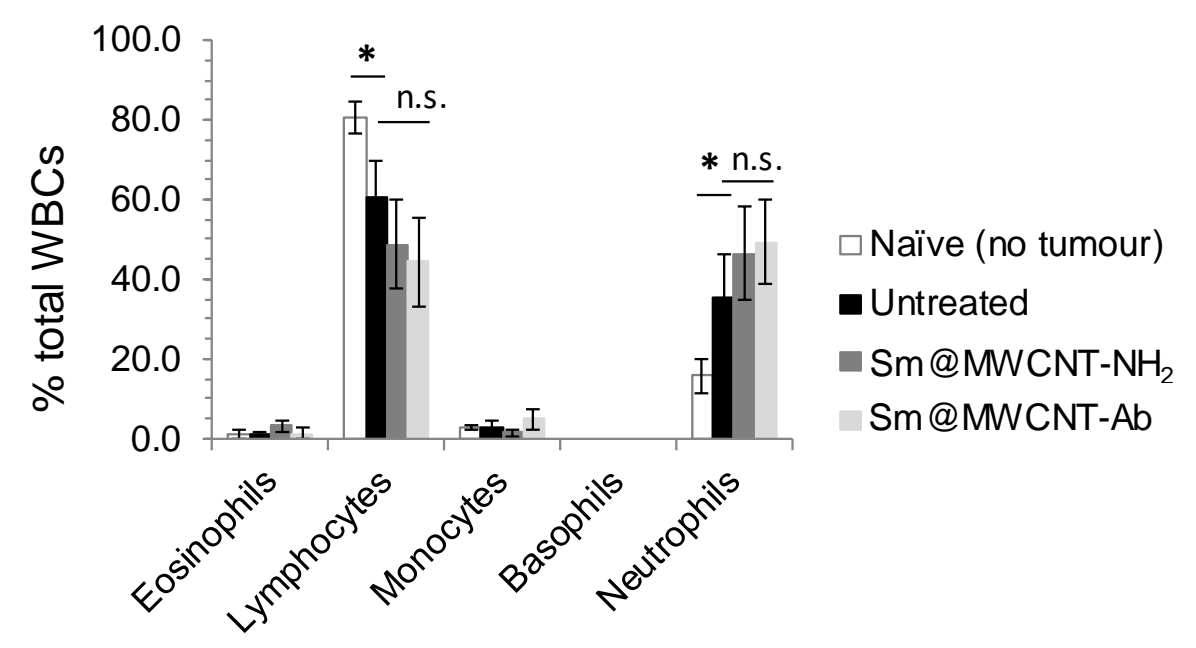




\section{Figure 8: Toxicity assessments after ${ }^{153} \mathrm{Sm@MWCNT-NH}$ and ${ }^{153} \mathrm{Sm} @ \mathrm{MWCNT}-\mathrm{Ab}$}

radiotherapy. (a) \% Whole body weight changes (b) organ weight and (c) white blood cell counts analysis after therapy. EGFR-expressing B16F10 metastatic lung tumour-bearing C57BL/6 mice were i.v injected with 15 MBq of ${ }^{153} \mathrm{Sm} @ \mathrm{MWCNT}-\mathrm{NH}_{2}$ and ${ }^{153} \mathrm{Sm} @ \mathrm{MWCNT}-\mathrm{Ab}(200 \mu \mathrm{g})$. Body weights were measured twice a week post-injection. Major organs and blood were sampled at experimental endpoint (Day 17 post-tumour inoculation). Blood smears were stained and examined by pathologists. Significant differences were examined using one-way ANOVA followed by Tukey's multiple comparison test (n.s.: non-significant, $* * p<0.01, * * * p<0.001$ ).

\subsection{Dosimetry simulation studies}

Figure 9 shows the model predictions of the tumour cell population based on the simple dosimetry model (Equation 1), assuming three different $\alpha / \beta$ ratios 1,2 or 3 which yielded $\alpha=0.0068,0.0102$ and 0.0122 , respectively. As can be seen, the best agreement was achieved for $\alpha=0.0068$ corresponding to the $\alpha / \beta$ ratio of 1 . Such a low value for the $\alpha / \beta$ ratio is indicative of a radioresistant cell population with high dose-rate sparing capacity. The minimum of surviving fraction for $\alpha=0.0068$ $\mathrm{Gy}^{-1}$ is only 0.77 whereas it is 0.26 and 0.13 for $\alpha=0.0102 \mathrm{~Gy}^{-1}$ and $\alpha=0.0122 \mathrm{~Gy}^{-1}$ respectively. The simple model qualitatively predicts that the administered radioactivity reduces significantly the rate of tumour growth compared to the 'no treatment' exponentially growing curve. However, it is also clear that the amount of administered activity is insufficient to overcome the effect of cell proliferation.

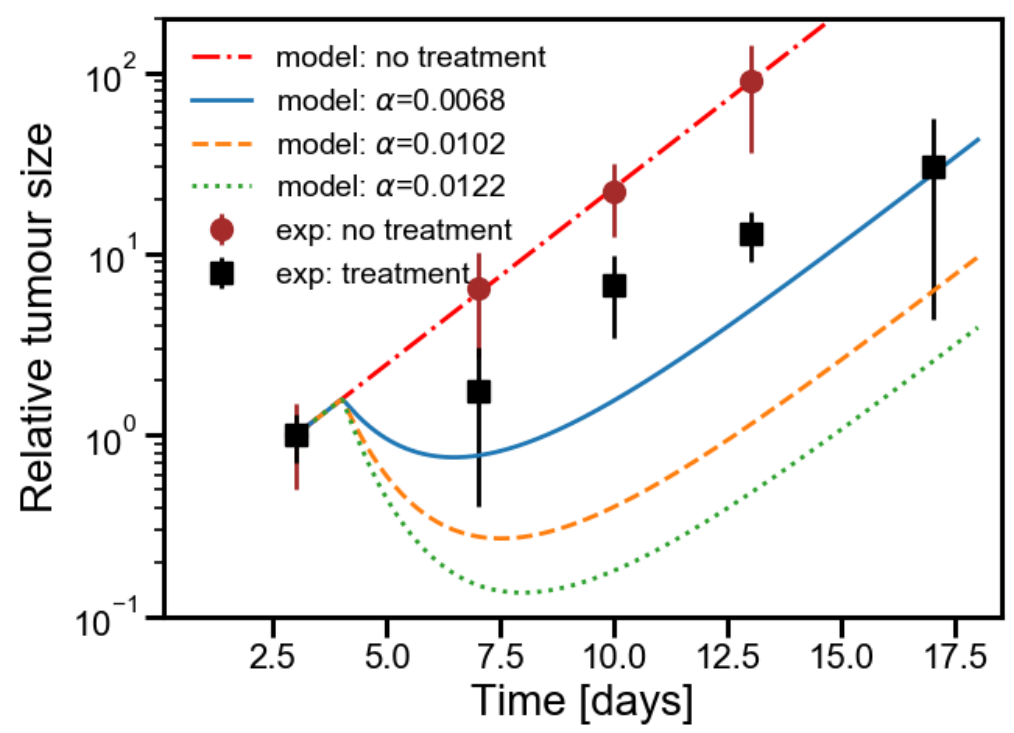




\section{Figure 9: Relative tumour size as a function of time after ${ }^{153} \mathrm{Sm} @ M W C N T-A b$ radiotherapy.}

EGFR-expressing B16F10-Luc tumour-bearing C57BL/6 mice received a single dose i.v. injection of ${ }^{153} \mathrm{Sm} @$ MWCNT-Ab (15 MBq, $\left.200 \mu \mathrm{g}\right)$ on Day 4 post-tumour inoculation. Black square dots represent experimental data and blue, green and orange lines are simulated results using different radiobiological parameters. The 'no treatment' line shows the predicted exponential growth if no activity is administered based on the fit of experimental data.

\section{Discussion}

With the rapid development in nanotechnology, nanomedicines have represented a promising layer in cancer diagnosis and therapy programmes, particularly aiming to enhance the treatment selectivity and specificity. As a natural consequence, an increasing number of studies have explored nanoparticle-mediated delivery platforms as a tool to deliver radionuclides for cancer radiotherapy [2-4].

Previously we developed a novel approach to engineer carbon nanocapsules packaging theranostic

${ }^{125}$ I (Auger and $\gamma$ emitter) by solution phase filling, followed by end-closing, without the need of using a chelator, to target lung tissues [25]. The construct underwent subsequent sugar functionalisation on the sidewall, thus improving water dispersibility and biocompatibility. Lung accumulation being attributed to the physical properties of the single-walled carbon nanocapsules within physiology [26]. Using fullerenes as corks, Pascu et al. have employed copper-64 filled nanocapsules for PET imaging [27]. Realising the importance of fast and safe manipulation of radiotherapeutics due to their constant decay, we further tailored this radioactive nanocapsule system by replacing ${ }^{125}$ I with stable ${ }^{152} \mathrm{Sm}$ and obtaining theranostic ${ }^{153} \mathrm{Sm}$ by neutron activation [11]. This approach allowed some of the lengthy preparation steps, such as filling of the CNTs and subsequent removal of non-encapsulated compounds $[16,28]$ to be done at ease with no time or radiological constraints. Neutron irradiation is performed on enriched nanocapsules, free of external material, and the subsequent external functionalization can be thus done within a suitable timeframe for patient use. Furthermore, tuning the radioactivity obtained in the resultant nanocapsules is possible by modifying the duration of neutron irradiation. The resulting high yields of specific radioactivity not only allowed SPECT/CT imaging but also made the nanocapsules therapeutically effective in delaying growth of metastatic lung tumours after single intravenous injection.

${ }^{153} \mathrm{Sm}$ is one of the bone-seeking radioisotopes used in clinic with the role in palliative treatment for patients with osteoblastic skeletal metastases such as breast cancer and multiple myeloma [29]. The 
usage is in the form of ${ }^{153} \mathrm{Sm}$-ethylenediaminetetramethylene phosphonate chelate with roughly half of the injection dose deposited to bone and the other half being excreted through renal clearance. The dominant bone uptake feature results in effective pain relief, but the applications are however limited. The ideal therapeutic distance of $\sim 1.01 \mathrm{~mm}$ and a half-life of $48.6 \mathrm{~h}$ should place ${ }^{153} \mathrm{Sm}$ in a better position in cancer management with wider applications [30]. The present study sets an example, delivering ${ }^{153} \mathrm{Sm}$ by nanoparticles to treat cancers other than skeletal metastases.

The multi-functional feature of nanoparticles enables further conjugation of targeting ligands which can potentiate the intracellular internalisation of nanoparticles to enhance their therapy specificity. This is particularly important for Auger particles with low radiation energies (20-500 eV) and limited ranges $(\sim 0.01 \mu \mathrm{m})$, restricting their therapeutic efficacy if not internalised into cells [31, 32]. There have been studies developing tumour targeting radioactive liposomes, polymeric nanoparticles or albumin particles that were chemically linked with folate, integrin antagonist or antibodies [5, 33, 34]. Following single injection (i.v. or i.p.) of targeting radionanoparticles incorporated with $\beta$ or $\beta / \gamma$ emitters such as ${ }^{90} \mathrm{Y}$ and ${ }^{131} \mathrm{I}$, significant tumour growth delay was achieved compared to non-targeted controls. We have previously exploited EGFR antibody-functionalised SWCNTs filled with radioactivable metals ${ }^{152} \mathrm{SmCl}_{3}$ or $\mathrm{LuCl}_{3}$ [12]. The results of enhanced cellular uptake in EGFR positive cancer cells prompted the current study to explore the system for tumour-targeted radiotherapy by means of neutron activation to yield high specific radioactivity.

To impart targeting capability, ${ }^{153} \mathrm{Sm} @ \mathrm{MWCNT}$ s were covalently functionalised with Cetuximab. CNTs were first functionalised by nitrene cycloaddition with a biocompatible triethylene glycol moiety bearing a protected primary amine with the double aim to improve the water dispersibility of the nanotubes and allow the covalent immobilisation of Cetuximab by subsequent amidation. After deprotection the amine functions reacted with the carboxylic acids of the antibody in the presence of coupling agents. Improved dispersibility in water or PBS was observed compared to the nonfunctionalised Sm@MWCNTs prepared in the previous study [11]. Indeed, 1\% Pluronic $®$ F-127 in saline was necessary to maintain a good suspension of non-functionalised Sm@SWCNTs and Sm@MWCNTs for injection, while in this study the dispersions of ${ }^{153} \mathrm{Sm} @ \mathrm{MWCNT}-\mathrm{NH}_{2}$ or ${ }^{153}$ Sm@MWCNT-Ab were prepared in PBS only. Without the use of Pluronic $®$ F-127 surfactant, it was possible to maintain a good suspension, indicating the improved dispersibility after functionalisation and antibody conjugation. 
A syngeneic B16F10-Luc-EGFR experimental melanoma lung metastasis model was chosen, taking advantage of the lung accumulation property of ${ }^{153} \mathrm{Sm} @$ MWCNTs observed previously [11]. EGFRexpressing tumour cells were employed in the current study to assess the targeting radiotherapeutic efficacy of ${ }^{153} \mathrm{Sm} @ \mathrm{MWCNT}-\mathrm{Ab}$. Prior to the therapy study, biodistribution profiles of ${ }^{153} \mathrm{Sm} @$ MWCNT-Ab were established in healthy and tumour-bearing mice. Comparable organ biodistribution pattern of ${ }^{153} \mathrm{Sm} @$ MWCNT-Ab was observed in both mice (Figure 4 and 5). Both types of functionalised ${ }^{153} \mathrm{Sm} @$ MWCNT-NH 2 and ${ }^{153} \mathrm{Sm} @$ MWCNT-Ab showed higher lung uptake and lower spleen accumulation compared to the first generation non-functionalised ${ }^{153} \mathrm{Sm} @$ MWCNTs [11]. Interestingly, in contrast to our previous report where spleen weight loss and abnormal histology were observed with non-functionalised ${ }^{153} \mathrm{Sm} @ \mathrm{MWCNTs}$, in this study, no significant spleen weight loss (Figure 8b) nor changes in haematological profiles (Figure 8c) were measured between untreated mice and mice treated with ${ }^{153} \mathrm{Sm} @ \mathrm{MWCNT}-\mathrm{NH}_{2}$ or ${ }^{153} \mathrm{Sm} @ \mathrm{MWCNT}$ Ab. Histological analysis further confirmed that normal microscopic features were observed in heart, liver, spleen and kidney tissue sections, suggesting no obvious toxicity. The decreased toxicity could be due to the lower radiation dose used in the current study (i.e. $15 \mathrm{MBq}$ vs $20 \mathrm{MBq}$ per mouse). It may also be attributed to the functionalisation of the ${ }^{153} \mathrm{Sm} @$ MWCNTs which has improved their biocompatibility overall. In our previous study investigating the immunological profiles of nonirradiated functionalised ${ }^{152} \mathrm{Sm} @$ SWCNT-Ab, no monocyte/macrophage depletion was observed in the mice treated with ${ }^{152} \mathrm{Sm} @ \mathrm{SWCNT}-\mathrm{NH}_{2}$ and ${ }^{152} \mathrm{Sm} @ \mathrm{SWCNT}-\mathrm{Ab}$ at day 1, 7 and 13 post-injection (150 $\mu \mathrm{g}$ /mouse), indicating their biocompatibility [35].

Dosimetry simulation model was established in this study based on a few assumptions and simplifications due to the limited available data as described in Experimental section. Our simple model omitted the complex nature of tumour cell behaviour, such as repair of radiation damage mechanisms, tumour blood supply and related variability radiosensitivity of hypoxic cells but was still able to qualitatively predict that the present level of the injected activity slows down the tumour growth. The model also enables to get approximate prediction of local tumour control. Here, we will define it as eradication of all clonogenic cells with $95 \%$ probability. Estimated number of cells in $0.05 \mathrm{~g}$ tumour is $5 \times 10^{7}$, and we will assume that they all proliferate. Expressing that in terms of surviving fraction, the required minimum surviving fraction is $S F<\frac{-\ln (0.95)}{5 \times 10^{7}} \approx 1 \times 10^{-9}$. The required intake was estimated iteratively until the minimum of surviving fraction was below this value. This is achieved for the administered activity of $130 \mathrm{MBq}$ for $\alpha=0.0068 \mathrm{~Gy}^{-1}$, or $90 \mathrm{MBq}$ for $\alpha=0.0102 \mathrm{~Gy}^{-1}$, or $75 \mathrm{MBq}$ for $\alpha=0.0122 \mathrm{~Gy}^{-1}$. 
Despite the fact that the radiation dose in the current work is a three-quarter of that used in our previous study due to some toxicity observed previously [11], remarkable therapeutic efficacy was shown in the mice receiving single injection of ${ }^{153} \mathrm{Sm} @ \mathrm{MWCNT}-\mathrm{NH}_{2}$ or ${ }^{153} \mathrm{Sm} @ \mathrm{MWCNT}-\mathrm{Ab}$ (Figure 6). By assessing the tumour growth rate between Day 7 and Day 17 post-tumour inoculation, the slope of the growth curve from untreated mice $\left(4.0 \times 10^{6}, \mathrm{R}^{2}=0.96\right)$ was $\sim 5$ times $\left(8.1 \times 10^{5}\right.$, $\left.\mathrm{R}^{2}=0.95\right)$ and $\sim 7$ times $\left(5.7 \times 10^{5}, \mathrm{R}^{2}=0.86\right)$ greater than the mice treated with ${ }^{153} \mathrm{Sm} @ \mathrm{MWCNT}-\mathrm{NH}_{2}$ and ${ }^{153} \mathrm{Sm} @$ MWCNT-Ab, respectively. In other words, although the given radioactivity dose might not be sufficient to achieve complete tumour regression, as also predicted by dosimetry simulation, it is obvious that tumours nearly remained dormant after the treatments of either ${ }^{153} \mathrm{Sm} @ \mathrm{MWCNT}-\mathrm{NH}_{2}$ or ${ }^{153} \mathrm{Sm} @$ MWCNT-Ab. The seemingly comparable anti-tumour efficacy observed for ${ }^{153} \mathrm{Sm} @ \mathrm{MWCNT}-\mathrm{NH}_{2}$ and ${ }^{153} \mathrm{Sm} @ \mathrm{MWCNT}-\mathrm{Ab}$ (days of growth delay, $p=0.35$ ) was however not surprising in view of the effective range of $\beta$ particle emitters which can release electrons in the distance up to several millimetres. ${ }^{153} \mathrm{Sm}$ emits $\beta$ particles within a range of $0.5 \mathrm{~mm}$ to $1.01 \mathrm{~mm}$ which is relatively smaller compared to other $\beta$ emitters (e.g. $12 \mathrm{~mm}$ for ${ }^{90} \mathrm{Y}$ and $5 \mathrm{~mm}$ for ${ }^{188} \mathrm{Re}[2,30]$ ). After all, most of the lung tissues (healthy and cancerous tissues), were likely to be covered by the radiation energy. With this regard, Auger emitters that deposit energy in extremely short distances may be better models for evaluating the targeting efficacy since the high density of radiation can ideally concentrate more on targeted tumour cells and spare the non-targeted healthy tissues during the therapy course.

However, $\beta$-emitting isotopes are exclusively used for RIT in clinic as their longer emission range is preferable to cover more of the tumour regions and possibly overcome the heterogeneity of uptake within the tumour [36]. ${ }^{131} \mathrm{I}$ is commonly used to treat thyroid cancer and its use in combination with antibody has granted FDA approval to treat lymphoma ( ${ }^{131}$ iodine- tositumomab, BEXXAR $\left.{ }^{\circledR}\right)$ [37]. ${ }^{90} \mathrm{Y}$ is a strong $\beta$-emitter and ${ }^{90} \mathrm{Y}$-labelled ibritumomab tiuxetan (Zevalin ${ }^{\circledR}$ ) is another approved targeted radionuclide for lymphoma [38]. ${ }^{177} \mathrm{Lu}$ is an example of medium-energy $\beta$-emitters and has been used in combination with prostate-specific membrane antigen (PSMA) ligands for treating prostate cancer [39]. Nanoparticles can certainly play a key role in this growing field of targeted RIT [40] to achieve specific tumour targeting either by passive targeting due to intrinsic properties (e.g. the enhanced accumulation and retention effect for PEGylated nanoparticles or the lung-targeting feature of the developed CNT) or by active targeting with an additional engineering of targeting ligands [2-4]. It is worth noting that ${ }^{153} \mathrm{Sm}$ and the above clinically commonly used three $\beta$-emitters also emit $\gamma$ rays so patients can be imaged and monitored by PET or SPECT during the treatment 
course. Moreover, these theranostic radionuclides are with high availability at relatively low cost as they can be produced with neutron activation [36].

It might not be in the immediate future for carbon materials to be translated clinically if administered systemically [41]. However, attributed to the superior in vivo stability, the developed carbon nanocapsules can be feasibly applied as implants for brachytherapy, a local radiation therapy for cancer in clinic. In the present study, we have produced antibody-conjugated radioactive carbon nanocapsules with high specific radioactivity suitable for cancer imaging and therapy. The advantages offered include the simplicity in materials filling and purification prior radiation, the tunable and less costly feature of neutron activation, and the appendment of biological ligands on radioactive capsules via fast chemical reactions. The concept, strategy and approaches developed may be readily applied to other nanomedicine systems for radiotherapy.

\section{Conclusions}

The present work developed tumour-targeted carbon nanocapsules encapsulating theranostic ${ }^{153} \mathrm{Sm}$ prepared by neutron activation. Tumour growth studies showed significant reduction after a single injection at a dose of $15 \mathrm{MBq}$, using an experimental lung metastatic melanoma model. The results demonstrated that our functionalisation strategy successfully improved the biocompatibility of the CNT conjugates, more specifically by reducing spleen and haematological toxicity, while not compromising the radiotherapeutic efficacy to effectively suppress the growth of melanoma lung metastasic tumour model. The established pharmacokinetics and dosimetry profiles could be useful for further application in other tumour models, species, and potentially for clinical applications.

\section{Declaration of competing interest}

The authors declare that they have no known competing financial interests or personal relationships that could have appeared to influence the work reported in this paper.

\section{Acknowledgements}

This work received funding from the European Union's Seventh Framework Programme (FP7-ITN Marie-Curie Actions, RADDEL, 290023). PM Costa would like to acknowledge the funding from the Wellcome Trust (WT103913). KT A-J would like to acknowledge the funding from Worldwide Cancer Research (12-1054). This work was partly supported by the Centre National de la Recherche Scientifique (CNRS), Agence Nationale de la Recherche (ANR) through the LabEx project Chemistry of Complex Systems (ANR-10-LABX-0026_CSC), and the International Center for Frontier 
Research in Chemistry (icFRC). ICMAB and ICN2 acknowledge financial support from the Spanish Ministry of Economy and Competitiveness, through the "Severo Ochoa" Programme for Centres of Excellence in R\&D (SEV-2015-0496 and SEV-2017-0706). We thank Thomas Swan Co. Ltd. for supplying CNT Elicarb® samples. We wish to acknowledge Cathy Royer and Valérie Demais for TEM analyses at the Plateforme Imagerie in Vitro at the Center of Neurochemistry (Strasbourg, France).

\section{References}

[1] D.A. Jaffray, M.K. Gospodarowicz, Chapter 14 Radiation Therapy for Cancer, 3rd ed., The International Bank for Reconstruction and Development / The World Bank, Washington (DC), 2015. [2] G. Song, L. Cheng, Y. Chao, K. Yang, Z. Liu, Emerging Nanotechnology and Advanced Materials for Cancer Radiation Therapy, Adv Mater 29(32) (2017) 1700996.

[3] L. Zhang, H. Chen, L. Wang, T. Liu, J. Yeh, G. Lu, L. Yang, H. Mao, Delivery of therapeutic radioisotopes using nanoparticle platforms: potential benefit in systemic radiation therapy, Nanotechnol Sci Appl 3 (2010) 159-170.

[4] J. Zhao, M. Zhou, C. Li, Synthetic nanoparticles for delivery of radioisotopes and radiosensitizers in cancer therapy, Cancer Nanotechnol 7(1) (2016) 9.

[5] M.E. Werner, S. Karve, R. Sukumar, N.D. Cummings, J.A. Copp, R.C. Chen, T. Zhang, A.Z. Wang, Folate-targeted nanoparticle delivery of chemo- and radiotherapeutics for the treatment of ovarian cancer peritoneal metastasis, Biomaterials 32(33) (2011) 8548-8554.

[6] L.-T. Lin, C.-H. Chang, H.-L. Yu, R.-S. Liu, H.-E. Wang, S.-J. Chiu, F.-D. Chen, T.-W. Lee, Y.J. Lee, Evaluation of the Therapeutic and Diagnostic Effects of PEGylated Liposome-Embedded ${ }^{188}$ Re on Human Non-Small Cell Lung Cancer Using an Orthotopic Small-Animal Model, J Nucl Med 55(11) (2014) 1864-1870.

[7] C.A. Boswell, X. Sun, W. Niu, G.R. Weisman, E.H. Wong, A.L. Rheingold, C.J. Anderson, Comparative in Vivo Stability of Copper-64-Labeled Cross-Bridged and Conventional Tetraazamacrocyclic Complexes, J Med Chem 47(6) (2004) 1465-1474.

[8] M. Zhou, R. Zhang, M. Huang, W. Lu, S. Song, M.P. Melancon, M. Tian, D. Liang, C. Li, A Chelator-Free Multifunctional $\left[{ }^{64} \mathrm{Cu}\right] \mathrm{CuS}$ Nanoparticle Platform for Simultaneous Micro-PET/CT Imaging and Photothermal Ablation Therapy, J Am Chem Soc 132(43) (2010) 15351-15358.

[9] T.M. Shaffer, M.A. Wall, S. Harmsen, V.A. Longo, C.M. Drain, M.F. Kircher, J. Grimm, Silica Nanoparticles as Substrates for Chelator-free Labeling of Oxophilic Radioisotopes, Nano Lett 15(2) (2015) 864-868. 
[10] A.J. Di Pasqua, H. Yuan, Y. Chung, J.-K. Kim, J.E. Huckle, C. Li, M. Sadgrove, T.H. Tran, M. Jay, X. Lu, Neutron-Activatable Holmium-Containing Mesoporous Silica Nanoparticles as a Potential Radionuclide Therapeutic Agent for Ovarian Cancer, J Nucl Med 54(1) (2013) 111-116.

[11] J.T.W. Wang, R. Klippstein, M. Martincic, E. Pach, R. Feldman, M. Šefl, Y. Michel, D. Asker, J.K. Sosabowski, M. Kalbac, T. Da Ros, C. Ménard-Moyon, A. Bianco, I. Kyriakou, D. Emfietzoglou, J.-C. Saccavini, B. Ballesteros, K.T. Al-Jamal, G. Tobias, Neutron Activated ${ }^{153} \mathrm{Sm}$ Sealed in Carbon Nanocapsules for In Vivo Imaging and Tumor Radiotherapy, ACS Nano 14(1) (2020) 129-141.

[12] C. Spinato, A. Perez Ruiz de Garibay, M. Kierkowicz, E. Pach, M. Martincic, R. Klippstein, M. Bourgognon, J.T.-W. Wang, C. Ménard-Moyon, K.T. Al-Jamal, B. Ballesteros, G. Tobias, A. Bianco, Design of antibody-functionalized carbon nanotubes filled with radioactivable metals towards a targeted anticancer therapy, Nanoscale 8(25) (2016) 12626-12638.

[13] M. Kierkowicz, E. Pach, A. Santidrián, S. Sandoval, G. Gonçalves, E. Tobías-Rossell, M. Kalbáč, B. Ballesteros, G. Tobias, Comparative study of shortening and cutting strategies of singlewalled and multi-walled carbon nanotubes assessed by scanning electron microscopy, Carbon 139 (2018) 922-932.

[14] M. Martincic, C. Frontera, E. Pach, B. Ballesteros, G. Tobias, Synthesis of dry $\mathrm{SmCl}_{3}$ from $\mathrm{Sm}_{2} \mathrm{O}_{3}$ revisited. Implications for the encapsulation of samarium compounds into carbon nanotubes, Polyhedron 116 (2016) 116-121.

[15] M. Martincic, S. Vranic, E. Pach, S. Sandoval, B. Ballesteros, K. Kostarelos, G. Tobias, Noncytotoxic carbon nanocapsules synthesized via one-pot filling and end-closing of multi-walled carbon nanotubes, Carbon 141 (2019) 782-793.

[16] M. Martincic, E. Pach, B. Ballesteros, G. Tobias, Quantitative monitoring of the removal of nonencapsulated material external to filled carbon nanotube samples, Phys Chem Chem Phys 17(47) (2015) 31662-31669.

[17] Manual for reactor produced radioisotopes, IAEA-TECDOC-1340, Vienna, Austria, 2003.

[18] C. Giulio, F. Simonelli, U. Holzwarth, P. Gibson, in: J. Llop-Roig, V. Gómez-Vallejo, N. Gibson (Eds.), Isotopes in Nanoparticles: Fundamentals and Applications, Pan Stanford Publishing Pte. Ltd.2016.

[19] A.C. Parente-Pereira, S. Wilkie, S.J.C. van der Stegen, D.M. Davies, J. Maher, Use of retroviralmediated gene transfer to deliver and test function of chimeric antigen receptors in human T-cells, $\mathrm{J}$ Biol Methods 1(2) (2014) e7.

[20] M. Šefl, I. Kyriakou, D. Emfietzoglou, Technical Note: Impact of cell repopulation and radionuclide uptake phase on cell survival, Med Phys 43(6) (2016) 2715-2720. 
[21] M.G. Stabin, M.W. Konijnenberg, Re-evaluation of absorbed fractions for photons and electrons in spheres of various sizes, J Nucl Med 41(1) (2000) 149-60.

[22] U. Schiller, W. Hoffmann, M. Bamberg, H.P. Rodemann, All-trans-retinoic acid modulates the radiosensitivity of proliferating cells, Int J Cancer 70(4) (1997) 488-90.

[23] J.D. Chapman, A.E. Nahum, Radiotherapy treatment planning: linear-quadratic radiobiology, CRC Press2015.

[24] R.G. Dale, Dose-rate effects in targeted radiotherapy, Phys Med Biol 41(10) (1996) 1871-84.

[25] S.Y. Hong, G. Tobias, K.T. Al-Jamal, B. Ballesteros, H. Ali-Boucetta, S. Lozano-Perez, P.D. Nellist, R.B. Sim, C. Finucane, S.J. Mather, M.L.H. Green, K. Kostarelos, B.G. Davis, Filled and glycosylated carbon nanotubes for in vivo radioemitter localization and imaging, Nat Mater 9(6) (2010) 485-490.

[26] S. De Munari, S. Sandoval, E. Pach, B. Ballesteros, G. Tobias, D.C. Anthony, B.G. Davis, In vivo behaviour of glyco-NaI@SWCNT ‘nanobottles', Inorganica Chimica Acta 495 (2019) 118933. [27] H. Ge, P.J. Riss, V. Mirabello, D.G. Calatayud, S.E. Flower, R.L. Arrowsmith, T.D. Fryer, Y. Hong, S. Sawiak, R.M.J. Jacobs, S.W. Botchway, R.M. Tyrrell, T.D. James, J.S. Fossey, J.R. Dilworth, F.I. Aigbirhio, S.I. Pascu, Behavior of supramolecular assemblies of radiometal-filled and fluorescent carbon nanocapsules in vitro and in vivo, Chem 3(3) (2017) 437-460.

[28] M. Kierkowicz, J.M. González-Domínguez, E. Pach, S. Sandoval, B. Ballesteros, T. Da Ros, G. Tobias, Filling Single-Walled Carbon Nanotubes with Lutetium Chloride: A Sustainable Production of Nanocapsules Free of Nonencapsulated Material, ACS Sustain Chem Eng 5(3) (2017) 2501-2508. [29] V.J. Lewington, Bone-Seeking Radionuclides For Therapy, J Nucl Med 46(1 suppl) (2005) 38S$47 \mathrm{~S}$.

[30] A. Goel, A. Dispenzieri, S.M. Geyer, S. Greiner, K.-W. Peng, S.J. Russell, Synergistic activity of the proteasome inhibitor PS-341 with non-myeloablative 153-Sm-EDTMP skeletally targeted radiotherapy in an orthotopic model of multiple myeloma, Blood 107(10) (2006) 4063-4070.

[31] M.P. Antosh, D.D. Wijesinghe, S. Shrestha, R. Lanou, Y.H. Huang, T. Hasselbacher, D. Fox, N. Neretti, S. Sun, N. Katenka, L.N. Cooper, O.A. Andreev, Y.K. Reshetnyak, Enhancement of radiation effect on cancer cells by gold-pHLIP, PNAS 112(17) (2015) 5372-5376.

[32] R.W. Howell, Auger processes in the 21st century, Int J Radiat Biol 84(12) (2008) 959-975.

[33] L. Li, C.A. Wartchow, S.N. Danthi, Z. Shen, N. Dechene, J. Pease, H.S. Choi, T. Doede, P. Chu, S. Ning, D.Y. Lee, M.D. Bednarski, S.J. Knox, A novel antiangiogenesis therapy using an integrin antagonist or anti-Flk-1 antibody coated ${ }^{90}$ Y-labeled nanoparticles, Int J Radiat Oncol Biol Phys 58(4) (2004) 1215-1227. 
[34] S. Liang, X. Jin, Y. Ma, J. Guo, H. Wang, Folic acid-conjugated BSA nanocapsule (n-BSA-FA) for cancer targeted radiotherapy and imaging, RSC Adv 5(108) (2015) 88560-88566.

[35] A. Perez Ruiz de Garibay, C. Spinato, R. Klippstein, M. Bourgognon, M. Martincic, E. Pach, B. Ballesteros, C. Ménard-Moyon, K.T. Al-Jamal, G. Tobias, A. Bianco, Evaluation of the immunological profile of antibody-functionalized metal-filled single-walled carbon nanocapsules for targeted radiotherapy, Sci Rep 7 (2017) 42605.

[36] W.A. Volkert, W.F. Goeckeler, G.J. Ehrhardt, A.R. Ketring, Therapeutic Radionuclides: Production and Decay Property Considerations, J Nucl Med 32(1) (1991) 174-185.

[37] R.M. Macklis, Iodine-131 tositumomab (Bexxar) in a radiation oncology environment, Int J Radiat Oncol Biol Phys 66(2, Supplement) (2006) S30-S34.

[38] T.E. Witzig, I.W. Flinn, L.I. Gordon, C. Emmanouilides, M.S. Czuczman, M.N. Saleh, L. Cripe, G. Wiseman, T. Olejnik, P.S. Multani, C.A. White, Treatment With Ibritumomab Tiuxetan Radioimmunotherapy in Patients With Rituximab-Refractory Follicular Non-Hodgkin's Lymphoma, J. Clin. Oncol., 20(15) (2002) 3262-3269.

[39] L. Emmett, K. Willowson, J. Violet, J. Shin, A. Blanksby, J. Lee, Lutetium ${ }^{177}$ PSMA radionuclide therapy for men with prostate cancer: a review of the current literature and discussion of practical aspects of therapy, J. Med. Radiat. Sci.64(1) (2017) 52-60.

[40] K. Zukotynski, H. Jadvar, J. Capala, F. Fahey, Targeted Radionuclide Therapy: Practical Applications and Future Prospects, Biomark Cancer 8(Suppl 2) (2016) 35-38.

[41] J.-C. Leroux, Editorial: drug delivery: too much complexity, not enough reproducibility? Angew. Chem. Int. Ed., 56(48) (2017) 15170-15171. 